\title{
Efficient Photocathodic Protection Enabled by a Multi-dimensional Quaternary
}

\section{Hybrid Superstructure}

Yunpeng Liu ${ }^{\text {a, } 1}$, Jianmin Lu ${ }^{\text {c, } 1 \text {, Wenlong Zhang }}{ }^{\text {a, } 1}$, Changzhen Lin ${ }^{\text {a }}$, Zhenyu Wang a , Xi Wang a , Hao Xu ${ }^{\text {a }}$, Jiangtao Feng ${ }^{a^{*}}$, Bo Hou ${ }^{b^{* *}}$ and Wei Yan ${ }^{a^{* * *}}$ and Zijun Ren ${ }^{d}$

a Department of Environmental Science \& Engineering, State Key Laboratory of Multiphase Flow in Power Engineering, School of Energy and Power Engineering, Xi' an Jiaotong University, Xi'an, 710049, China. Email: fjtes@xjtu.edu.cn; yanwei@xjtu.edu.cn

b School of Physics and Astronomy, Cardiff University, The Parade, Cardiff, CF24 3AA, Wales, UK. Email: HouB6@cardiff.ac.uk

c State Key Laboratory of Catalysis, Dalian National Laboratory for Clean Energy, Dalian Institute of Chemical Physics, Chinese Academy of Sciences, Dalian 116023, China.

d Instrument Analysis Center of Xi'an Jiaotong University, Xi'an Jiaotong University, Xi'an, 710049, China

1 These authors contributed equally to this work.

Corresponding authors:

Jiangtao Feng: fjtes@xjtu.edu.cn

Bo Hou: $\underline{\text { HouB6@eardiff.ac.uk }}$

Wei Yan: yanwei@,xjtu.edu.cn 
Abstract: The global annual steel waste associate with interface corrosion represent significant challenges for steel's lifetime as well as sustainable development of modern society. Herein, we report a unique multi-dimensional quaternary hybrid superstructure for photocathodic protection (PCP) which not only has an intense visible to nearinfrared absorptivity for generating 'hot' electrons but also can provide time-delay anticorrosion functions in the dark. We exemplified the PCP performance of this quaternary composite on a typical 304 stainless steel (304SS) which results in its surface potential shifting negatively by about $660 \mathrm{mV}$ compared to its natural corrosion potential under visible light illumination. Besides, time-delay protection without illumination is also demonstrated, which is resulted from the "electron pool" effect associates to the embedded zero-dimensional quantum dots. Based on density functional theory (DFT) simulations as well as comprehensive electron microscopy studies, we elucidate the origin of the enhanced PCP performances are attributed to the improved work per photon using 'hot' carriers, which surpass the limit of the state-of-the-art PCP technologies. In addition, we found the use of one-dimensional titanium dioxide nanorods and two-dimensional reduced graphene oxide as a scaffold can structure the metal nanoparticles and forces photoinduced 'hot' electrons to transfer to the functionalized 304SS. Various promising functionalities arises from the use of asproposed multi-dimensional quaternary superstructure as a sustainable anti-corrosion material can be envisioned.

Keywords: 'hot' carriers, time-delay protection, 304 stainless steel, photocathodic protection, DFT 


\section{Introduction}

With the rapid development of the modern steel industry, the demand for materials sustainability has also been increased dramatically. In particular, the localized corrosion in 304 stainless steel (304SS) significantly limits its lifetime and broad deployment, especially in the marine environment $[1,2]$. Therefore, it is of great importance to find practical approaches to advance the corrosion resistance of 304SS toward the sustainable development of the steel industry as well as reduce the greenhouse gas emission during the steel reproduction. Recently, many technologies have been developed to solve the corrosion problem, such as corrosion inhibitors [3, 4], anticorrosion coatings $[5,6]$, electrochemical protection $[7,8]$. As a green and promising approach, photocathodic protection (PCP) has also received considerable interest over the past decades [9-11]. In the PCP process, the semiconductor material serves as the photoanode, which can produce the photogenerated electrons $/$ holes $\left(\mathrm{e}^{-} / \mathrm{h}^{+}\right)$pairs under solar light illumination. The electrons can diffuse to the coupled metal, and shift its surface potential lower than oxidation potential, which enables the metal corrosion to be inhibited [12-14].

Titanium dioxide $\left(\mathrm{TiO}_{2}\right)$ has attracted extensive attention as an efficient PCP material due to its low cost and good photosensitivity [15-17]. Among its numerous existing structures, one-dimensional (1D) $\mathrm{TiO}_{2}$ nanorods (TNRs) exhibit good PCP performance associated with its symmetrical 1D structural design that can suppress the $\mathrm{e}^{-} / \mathrm{h}^{+}$pairs recombination effectively [18]. However, the intrinsic bandgap of $\mathrm{TiO}_{2}$ is relatively large $(>3 \mathrm{eV})$ which only covers a small portion of the solar spectrum [19], and it also 
cannot provide time-delay protection after switching off the light [20].

Zero-dimensional (0D), noble metal nanoparticles (NPs), such as Au, Ag, Pt and Pd have been proposed to modify TNRs [21-24], because the PCP performance can be improved by using the additional 'hot' electrons generated from surface plasmonic resonance (SPR) effect [25]. These 'hot' electrons have considerable more kinetic energy than those electrons generated by direct band edge photoexcitation [26, 27]. Many studies show 'hot' electrons can transfer from noble metals to adjoined semiconductors for metal-semiconductor hybrids to enhances photocatalytic activities [28-30]. Moreover, the large Schottky barrier between Au-NPs and TNRs can eliminate $\mathrm{e}^{-} / \mathrm{h}^{+}$pairs recombination to improve the exciton disassociation efficiency [31]. Wang et al. [32] and Liu et al. [33] have successfully demonstrated that Au-NPs modified TNRs film can improve the photodecomposition efficiency of organic compounds (glucose and methyl orange, respectively). However, in terms of PCP, the injection rate of 'hot' electrons from Au-NPs to TNRs is still relatively low, which results in less improvement in photo-to-electron conversion efficiency [34]. Furthermore, the small 'electron-storage capacity' of Au-NPs/TNRs film also cannot provide time-delay protection for 304SS under dark condition [33]. Therefore, it is essential to insert an electron transport layers between Au-NPs/TNRs binary composites to improve the electron transfer efficiency as well as to improve time-delay protection under dark.

Reduced graphene oxide (rGO), a new class of two-dimensional (2D) carbon material, has been widely studied in the photoelectrochemical field due to its large surface area as well as high conductivity [35]. There are also potential advantages if 
one can combine rGO sheets with Au-NPs/TNRs film. Firstly, the planar $\pi-\pi$ conjunction structure of rGO can capture and facilitate charge transport [36], which can serve as an excellent electron transport layer for depleting photogenerated $\mathrm{e}^{-} / \mathrm{h}^{+}$pairs in Au-NPs/rGO/TNRs composite films [37]. Secondly, the visible-light response of TNRs can be dramatically enhanced because of the sensitizing effect of rGO [38]. Thirdly, the large specific surface area of rGO can provide more surface deposition sites for AuNPs, to further increase the SPR effect of the composite film. Therefore, the present of rGO layers can improve PCP performance mediated by the enhanced photocurrent injection rate from $\mathrm{Au}-\mathrm{NPs}$ to TNRs. Li et al. introduced the $\mathrm{rGO}$ interlayer between CdSe and $\mathrm{TiO}_{2}$ film, which realized a high electron transfer efficiency and good PCP performance [39]. However, efficient time-delay protection is still not realized, which cannot provide anti-corrosion protection in the dark.

Tin oxide $\left(\mathrm{SnO}_{2}\right)$ is another promising n-type semiconductor (bandgap 3.5-3.6 eV) for PCP application [40], and a type-II heterojunction can be formed between $\mathrm{SnO}_{2}$ and $\mathrm{TiO}_{2}$. [41] Recently, Huy et al. [42] and Sun et al. [43] synthesized a $\mathrm{SnO}_{2}$ quantum dots (QDs) modified TNRs film and demonstrated outstanding water splitting photocatalytic performance. Besides, the conduction band $(\mathrm{CB})$ of $\mathrm{SnO}_{2}$ can act as "electron pool" to partially store photoexcited electrons when the composite film is under irradiance and then releases the stored charges to the coupled steel after cutting off the light $[40,44$, 45]. In other words, $\mathrm{SnO}_{2}$-based materials can provide continuous protection to the steel, even in the dark [46-48]. Therefore, exploring an efficient approach to use $\mathrm{SnO}_{2}$ and other photoanodes as PCP materials is highly promising. 
In this work, we propose a 0D-1D-2D multi-dimensional quaternary Au$\mathrm{NPs} / \mathrm{rGO} / \mathrm{SnO}_{2}$ QDs/TNRs (AGSQT NRs) superstructure (Scheme 1) as a unique material platform for PCP, which exhibits an outstanding performance for 304SS protection beyond most of the previously reported works. For the first time, we demonstrate the photocathodic protection of 304SS using the quaternary AGSQT NRs hybrid composite film, which shows improvement not only in PCP efficiency but also in time-delay protection. A series of advanced spectroscopy and microscopy techniques were used to understand the unique crystalline structure, surface morphology, chemical composition and optical properties of the as-proposed quaternary superstructure. DFT calculation was also employed to simulate the evolution of the electronic structures as a function of hybrid compositions, which provides a theoretical model to elucidate the PCP anti-corrosion mechanism for 304SS. 


\section{Experimental}

The detail information of chemicals, instruments, and DFT computation methods were listed in the Electronic Supporting Information (ESI).

\subsection{Synthesis method}

Preparation of TNRs film: The TNRs film was synthesized on an FTO glass via the hydrothermal method using the following procedures [49]. Firstly, $60 \mathrm{~mL}$ of $\mathrm{HCl}$ aqueous solution $\left(6 \mathrm{~mol} \cdot \mathrm{L}^{-1}(\mathrm{M})\right)$ mixed with $1.0 \mathrm{~mL} \mathrm{C} \mathrm{C}_{16} \mathrm{H}_{36} \mathrm{O}_{4} \mathrm{Ti}$ was transferred into a $100 \mathrm{~mL}$ Teflon-lined stainless-steel autoclave. Then a piece of FTO glass was placed at an angle (60 degrees) against the wall of the above autoclave with the conducting side facing down and heated at $150{ }^{\circ} \mathrm{C}$ for $10 \mathrm{~h}$ in an electric oven. After the reaction, the sample was rinsed with DIW, and then calcined in a muffle furnace at $500{ }^{\circ} \mathrm{C}$ for $2 \mathrm{~h}$ in the air.

Preparation of $\mathrm{SnO}_{2}$ QDs/TNRs binary composite film: $\mathrm{SnO}_{2}$ QDs were decorated on the TNRs film by an in-situ impregnation method [50]. The TNRs film was statically immersed in the solution of $0.01 \mathrm{M} \mathrm{SnCl}_{2}(0.02 \mathrm{M} \mathrm{HCl})$ under ambient condition. After impregnating for $5 \mathrm{~h}$, the sample was washed with DIW and then dried in ambient air. Finally, those samples were calcined at $400{ }^{\circ} \mathrm{C}$ for $2 \mathrm{~h}$ in the air.

Preparation of $\mathbf{r G O} / \mathrm{SnO}_{2}$ QDs/TNRs ternary composite film: The rGO layer was electrochemically deposited [51] onto the surface of $\mathrm{SnO}_{2}$ QDs/TNRs film using a power supply (JBP-15005, Shanghai Jiangbo electronics technology, China). Typically, in a two-electrode system, $\mathrm{SnO}_{2} \mathrm{QDs} / \mathrm{TNRs}$ film and Pt foil served as the working electrode (WE) and the counter electrode (CE), respectively. $50 \mathrm{mg}$ of GO powder was 
added to $20 \mathrm{~mL}$ of DIW, and this solution was ultrasound for $1 \mathrm{~h}$ to obtain GO dispersions, which served as the electrolyte. The anodization process was performed at $30 \mathrm{~V}$ for $15 \mathrm{~min}$. The composite film sample was rinsed with DIW and then dried in the air, followed by annealing at $200{ }^{\circ} \mathrm{C}$ in the air for $1 \mathrm{~h}$.

Preparation of quaternary AGSQT NRs hybrid composite film: According to previous literature [52], Au-NPs were anchored on the rGO layer via a solution thermal reduction method. The $\mathrm{rGO} / \mathrm{SnO}_{2}$ QDs/TNRs composite film was immersed in 0.010 $\mathrm{M} \mathrm{HAuCl}_{4}$ solutions $(\mathrm{pH}=7)$ for $4 \mathrm{~h}$. Then this film was taken out and cleared by DIW. The air-dried film was then calcined for $2 \mathrm{~h}$ at $200{ }^{\circ} \mathrm{C}$ in air.

\subsection{Photoelectrochemical tests}

As shown in Fig. S1, all the photoelectrochemical tests were performed on the CHI660D electrochemical workstation (Shanghai Chinstrument Co. Ltd, China) using a double electrolytic cell setup, which was consisted of a corrosion cell $(3.5 \mathrm{wt} \% \mathrm{NaCl}$ solution), a photoelectrochemical cell ( $0.1 \mathrm{M} \mathrm{Na}_{2} \mathrm{~S}$ and $0.2 \mathrm{M} \mathrm{NaOH}$ mixed solution) and two couple cells connected by a U-type salt bridge (a flexible glass tube with 1.0 $\mathrm{M} \mathrm{KCl}$ in agar). In the corrosion cell, a traditional conventional three-electrode system was used, in which the 304SS electrode, $\mathrm{Ag} / \mathrm{AgCl}$ electrode and $\mathrm{Pt}$ foil were served as the WE, RE and CE, respectively. Meanwhile, the as-prepared film was immersed in the electrolyte of a photoelectrochemical cell as the photoanode, connected with the 304SS by a copper wire. Photoelectrochemical measurements were investigated under intermittent visible light $\left(100 \mathrm{~mW} \cdot \mathrm{cm}^{-2}\right.$, a $500 \mathrm{~W}$ xenon lamp, CHF-XM-500W, Beijing Changtuo Technology Co., Ltd. Beijing, China) equipped with a UV cut-off filter $(\lambda>$ 
$420 \mathrm{~nm}$ ). The open-circuit potential (OCP) and Tafel curve were tested with the scanning rate of $1 \mathrm{mV} \cdot \mathrm{s}^{-2}$, and the photocurrent density of the sample was also collected without applying a bias voltage. The electrochemical impedance spectroscopy (EIS) were tested at OCP over a frequency range of $10^{5}$ to $10^{-2} \mathrm{~Hz}$ with a $10 \mathrm{mV}$ AC amplitude. The Tafel result was fitted to calculate the corrosion potential $\left(\mathrm{E}_{\text {corr }}\right)$ and the corrosion current density $\left(\mathrm{j}_{\text {corr }}\right)$. The active area of $304 \mathrm{SS}$ and as-prepared samples were $1 \mathrm{~cm}^{2}$, and the 304SS were polished with abrasive paper before using it.

\section{Results and discussion}

\subsection{Structural characteristics}

The Raman spectra of the TNRs, $\mathrm{SnO}_{2}$ QDs/TNRs, $\mathrm{rGO} / \mathrm{SnO}_{2}$ QDs/TNRs and AGSQT NRs composite films were collected to investigate the composition-dependent lattice variation. As shown in Fig. 1a, three sharp peaks are observed at 233, 448 and $603 \mathrm{~cm}^{-1}$, which can be ascribed to the characteristic $\mathrm{B}_{1 \mathrm{~g}}, \mathrm{E}_{\mathrm{g}}$ and $\mathrm{A}_{\mathrm{lg}}$ modes of rutile $\mathrm{TiO}_{2}$, respectively [53]. However, the characteristic anatase $\mathrm{TiO}_{2}$ Raman peaks are absent from the spectra, which confirms that as-prepared TNRs is a rutile structure. Because of the extremely high peak intensity as well as similar Raman peak positions between $\mathrm{SnO}_{2}$ and $\mathrm{TiO}_{2}$, no noticeable difference can be found among the curves for the other samples [54]. It should be noted that the AGSQT NRs peak intensities are higher than those of $\mathrm{rGO} / \mathrm{SnO}_{2}$ QDs/TNRs because of the significant enhancement of Raman signal by Au-NPs (1200-1700 $\mathrm{cm}^{-1}$, Fig. 1b) [55]. The D band $\left(\sim 1350 \mathrm{~cm}^{-1}\right)$ and G band $\left(\sim 1580 \mathrm{~cm}^{-1}\right)$ of graphene materials can also be observed (Fig. 1c), which corresponds to the number of defects or the edge of the reacted graphite layer, and $\mathrm{sp}^{2}$ 
hybrid carbon atoms, respectively [56]. The values of $\mathrm{I}_{\mathrm{D}} / \mathrm{I}_{\mathrm{G}}$ of $\mathrm{GO}, \mathrm{rGO} / \mathrm{SnO}_{2}$ QDs/TNRs and AGSQT NRs are 0.92, 0.44 and 0.43, respectively. The decreasing trend of $\mathrm{I}_{\mathrm{D}} / \mathrm{I}_{\mathrm{G}}$ ratio demonstrates the reduction of oxygen-containing functional groups and restoration of $\mathrm{sp}^{2}$ network in $\mathrm{rGO}$ [57], which implies the reduction process of GO during the thermal treatment. Through the transformation from an insulator (GO) to a conductor (rGO), the electrical property of GO can be altered, which can realize the capture and transfer of 'hot' electrons from Au-NPs effectively[58].

The XRD patterns of the TNRs, $\mathrm{SnO}_{2}$ QDs/TNRs, $\mathrm{rGO} / \mathrm{SnO}_{2}$ QDs/TNRs and quaternary AGSQT NRs composite films are displayed in Fig. 1d. The diffraction peaks of the TNRs at $27.5^{\circ}, 36.2^{\circ}, 39.2^{\circ}, 41.3^{\circ}, 54.4^{\circ}, 62.9^{\circ}$ and $69.2^{\circ} 2 \theta$ positions correspond to the (lll $\left.1 \begin{array}{ll}1 & 0\end{array}\right),\left(\begin{array}{lll}1 & 0 & 1\end{array}\right),\left(\begin{array}{lll}2 & 0 & 0\end{array}\right),\left(\begin{array}{lll}1 & 1 & 1\end{array}\right),\left(\begin{array}{lll}2 & 1 & 1\end{array}\right),\left(\begin{array}{lll}0 & 0 & 2\end{array}\right)$ and $\left(\begin{array}{lll}3 & 0 & 1\end{array}\right)$ planes of rutile $\mathrm{TiO}_{2}$ (JCPDS Card No. 65-0912), respectively [59]. After the deposition of $\mathrm{SnO}_{2}$ QDs on the surface of $\mathrm{TiO}_{2}$ nanorod, the new peaks at $2 \theta=33.9^{\circ}, 61.9^{\circ}$ and $65.9^{\circ}$ can be indexed to (lll $\left.\begin{array}{lll}1 & 0 & 1\end{array}\right),\left(\begin{array}{lll}3 & 1 & 0\end{array}\right)$ and ( $\left(\begin{array}{lll}3 & 0 & 1\end{array}\right)$ planes from cassiterite $\mathrm{SnO}_{2}$ (JCPDS Card No. 41-1445) [60]. This result indicates that $\mathrm{Sn}^{2+}$ is oxidized to $\mathrm{SnO}_{2}$ by in-situ impregnation method, confirming the formation of the $\mathrm{SnO}_{2}$ QDs/TNRs composite film. The $\mathrm{rGO} / \mathrm{SnO}_{2}$ QDs/TNRs composite film shows a characteristic peak of $\mathrm{rGO}$ at $24.2^{\circ}$ [61], further confirms the successful generation of rGO and good affinity between rGO layer and $\mathrm{SnO}_{2}$ QDs/TNRs film. In XRD pattern of quaternary AGSQT NRs, additional diffraction peaks at $2 \theta$ values of $38.3^{\circ}$ and $44.5^{\circ}$ are assigned to the (llll 111$)$ and $\left(\begin{array}{lll}2 & 0 & 0\end{array}\right)$ planes of the cubic Au-NPs, separately [30]. Compared to XRD pattern (Fig. 1e) of AGSQT NRs with that of GO, the disappearance of the major peak at $2 \theta=11.0^{\circ}$ 
(corresponding to the ( $\left(\begin{array}{lll}0 & 0 & 2\end{array}\right)$ diffraction of GO) further proves the transformation from GO to rGO during the thermal treatment [57].

The morphologies of TNRs, $\mathrm{SnO}_{2} \mathrm{QDs} / \mathrm{TNRs}, \mathrm{rGO} / \mathrm{SnO}_{2} \mathrm{QDs} / \mathrm{TNRs}$ and quaternary AGSQT NRs films were characterized via SEM under different magnifications. As shown in Fig. 2a, uniform and dense TNRs with an average diameter of $150 \pm 5 \mathrm{~nm}$ can be resolved. The cross-section image (Fig. S2a) of the TNRs shows that the average length of nanorods is $5.27 \pm 0.03 \mu \mathrm{m}$, and these nanorods are nearly perpendicular to the FTO substrate. The top-view SEM image (Fig. 2b) exhibits further detail morphological information of as-prepared composite film such as the embedded $\mathrm{SnO}_{2}$ QDs. Fig. 2c shows a typical transparent and continuous 2D rGO film which was formed after thermal treatment of GO. As shown in Fig. 2d, the characteristic wrinkle features of rGO can be observed, which provides additional anchored sites for Au-NPs. Through the thermal reduction deposition, Au-NPs can be successfully loaded onto the surface of $\mathrm{rGO} / \mathrm{SnO}_{2}$ QDs/TNRs film (Fig. 2e and Fig. 2f), with negligible damage to the wrinkle features. Fig. $2 \mathrm{~g}$ shows the high-resolution SEM image of the quaternary AGSQT NRs films, which shows the monodispersed feature of as-prepared Au-NPs can be resolved. The particle size of the Au-NPs is estimated to be $19.5 \mathrm{~nm}$ by averaging among 100 NPs (Fig. 2h). Meanwhile, the cross-view SEM image of quaternary AGSQT NRs (Fig. S2b) demonstrates that the unique 1D morphology is well-preserved during the multiple deposition processes.

The microstructure of TNRs, $\mathrm{SnO}_{2}$ QDs/TNRs, $\mathrm{rGO} / \mathrm{SnO}_{2}$ QDs/TNRs and quaternary AGSQT NRs films were further characterized by TEM and high-resolution 
TEM (HRTEM). As shown in Fig. 3a, the typical 1D rod-like morphology of asprepared TNRs film can be revealed. The HRTEM (Fig. 3b) and SAED (Fig. S3) results further confirm the single-crystalline rutile characteristics of as-prepared $\mathrm{TiO}_{2}$ nanorod. The $0.32 \mathrm{~nm}$ interplanar spacing can be readily indexed to the rutile- $\mathrm{TiO}_{2}\left(\begin{array}{lll}1 & 1 & 0\end{array}\right)$ lattice constant, which further demonstrates the preferable growth along with the $\left[\begin{array}{lll}0 & 0 & 1\end{array}\right]$ zone axis [62]. Fig. 3c shows that there is negligible morphology alternation after the deposition of $\mathrm{SnO}_{2}$ QDs onto TNRs. Moreover, it can be seen that the average diameter of the $\mathrm{SnO}_{2}$ nanoparticles is only $\sim 6.0 \mathrm{~nm}$ (Fig. $3 \mathrm{~d}$ ), which falls in the regime of QDs [63-65]. The HRTEM images (Fig. 3e and Fig. 3f) display well-resolved lattice spacings of $0.33 \mathrm{~nm}$ and $0.24 \mathrm{~nm}$, which match well with the $\left(\begin{array}{lll}1 & 1 & 0\end{array}\right)$ and $\left(\begin{array}{lll}2 & 0 & 0\end{array}\right)$ planes of cassiterite $\mathrm{SnO}_{2}$ [66]. The HRTEM analysis results are consistent with XRD data which confirm the successful deposition of $\mathrm{SnO}_{2}$ QDs on the surface of the $\mathrm{TiO}_{2}$ nanorod. As shown in Fig. $3 g$ and Fig. 3h, transparent few-layer graphene can be found on the TNRs, which coincides with our observations in SEM and Raman characterizations. Lowresolution TEM images of quaternary AGSQT NRs films (Fig. 3i, Fig. 3j and Fig. 3k) also resolve near-spheroidal nanocrystals anchored on the 2D rGO sheet. As indexed in the HRTEM image (Fig. 31), these nanocrystals are attributed to Au-NPs since their lattice fringes $(0.23 \mathrm{~nm}, 0.20 \mathrm{~nm}$ and $0.15 \mathrm{~nm})$ fits well with the $\mathrm{Au}\left(\begin{array}{lll}1 & 1 & 1\end{array}\right),\left(\begin{array}{lll}2 & 0 & 0\end{array}\right)$ and (2 2 0) lattice constants [67]. Electron microscopy analysis confirms that the $\mathrm{HAuCl}_{4}$ precursor is successfully converted to metallic Au-NPs during the hydrothermal reduction process. The close contact between Au-NPs and rGO enables efficient 'hot' electrons transportation from the 0D Au-NPs to 2D rGO layer, which is crucial to the 
high PCP performance of the AGSQT NRs film. Besides, the existence of folds and wrinkles features indicates the few-layer nature of as-deposited $\mathrm{rGO}$, which is not only beneficial for Au-NPs implantation but also facilitate plasmonic visible light absorption towards excellent PCP performance.

Fig. 4 shows the XPS spectra of as-prepared films which are used to investigate the chemical composition of each component. Fig. 4a displays the XPS survey spectrum of the AGSQT NRs film over a broad energy range, which shows Ti 2p, Sn 3d, Au 4f, O 1s and C 1s peaks without any impurities. As shown in curve (I) of Fig. 4b, the Ti $2 p$ spectrum (Fig. 4b) of the TNRs is divided into two binding energy peaks (Ti $2 \mathrm{p}_{1 / 2}$ and Ti $2 p_{3 / 2}$ ) [18], which indicates the oxidation state of Ti is +4 . As shown in Fig. $4 b$, the continuous negative shift of $\mathrm{Ti} 2 \mathrm{p}_{1 / 2}$ and $\mathrm{Ti} 2 \mathrm{p}_{3 / 2}$ peaks from curve (I) to curve (IV), indicates the electrons transfer process between $\mathrm{Au}, \mathrm{SnO}_{2}, \mathrm{rGO}$ and $\mathrm{TiO}_{2}$. The highresolution XPS spectrum of $\mathrm{Sn} 3 \mathrm{~d}$ is shown in Fig. 4c. The indexed binding energy of $495.21 \mathrm{eV}$ and $486.85 \mathrm{eV}$ could be assigned to $\mathrm{Sn} 3 \mathrm{~d}_{3 / 2}$ and $\mathrm{Sn} 3 \mathrm{~d}_{5 / 2}$, respectively [42], which manifests the presence of the $\mathrm{SnO}_{2}$ in AGSQT NRs film. In Fig. 4d, peaks of $\mathrm{Au}^{0}$ $4 \mathrm{f}_{7 / 2}$ and $\mathrm{Au}^{0} 4 \mathrm{f}_{5 / 2}$ are centered at $83.38 \mathrm{eV}$ and $86.99 \mathrm{eV}$, and the spin-orbit separation is $3.61 \mathrm{eV}$. The result suggests the metallic state of Au-NPs in the composite film [33], agrees well with the XRD and HRTEM results. The O 1s signals at 530.5, 532.1 and $533.6 \mathrm{eV}$ (Fig. 4e) are attributed to the unique metal-oxygen bonds, the bonds of rGO (C-O \& $\mathrm{C}=\mathrm{O})$, and surface hydroxyl oxygen $(\mathrm{O}-\mathrm{OH})$ respectively [68]. The highresolution C 1s XPS spectrum for AGSQT NRs film can be divided into three peaks, as shown in Fig. 4f. The dominant peak with the binding energy at $284.8 \mathrm{eV}$ is assigned 
to non-oxygenated $\mathrm{C}-\mathrm{C}$ and $\mathrm{sp}^{2}$ hybridized carbon $(\mathrm{C}=\mathrm{C})$ bonds. Also, other oxygencontaining carbonaceous bonds located at $286.4 \mathrm{eV}$ are ascribed to the $\mathrm{C}-\mathrm{O}$ bond (hydroxyls attached to graphene or epoxy groups, for example), while the broad peak located at $288.4 \mathrm{eV}$ is attributed to carboxylate carbon $(\mathrm{O}=\mathrm{C}-\mathrm{O})$ [69-71]. Comparisons between carbon-containing functional groups of GO and AGSQT NRs film are displayed in Table S1 and Fig. S4. It can be seen that the amount of C-O reduces from $36.8 \%$ to $8.0 \%$. However, the amount of $\mathrm{O}=\mathrm{C}-\mathrm{O}$ remains stable at $6.5-7.3 \%$, which suggests the extreme stability of the carboxylic group at the edge of GO layer. Meanwhile, this result further confirms the transformation from GO to rGO [72]. Additionally, the noticeably increased proportion of the $\mathrm{C}-\mathrm{C}$ and $\mathrm{C}=\mathrm{C}$ (from 55.9 to $66.7 \%$ ) suggests a restoration of the $\mathrm{sp}^{2}$ bonded $\mathrm{C}$ atoms in $\mathrm{GO}$, and a rearrangement of the graphene structure during the reduction process, which is consistent with the result of the above Raman analysis. Therefore, the XPS results together with electron microscopy, XRD and Raman characterizations, demonstrate the successful formation of quaternary AGSQT NRs hybrid superstructure.

The UV-visible diffuse reflectance spectra (DRS) of the TNRs, $\mathrm{SnO}_{2} \mathrm{QDs} / \mathrm{TNRs}$, $\mathrm{rGO} / \mathrm{SnO}_{2}$ QDs/TNRs and AGSQT NRs film samples are displayed in Fig. 4g. All the samples exhibit similar absorption intensity in the UV region. TNRs film shows a typical absorption onset at about $410 \mathrm{~nm}$ corresponding to the optical bandgap $(3.0 \mathrm{eV})$ of rutile $\mathrm{TiO}_{2}$ [73]. After the deposition of $\mathrm{SnO}_{2}$ QDs, the $\mathrm{SnO}_{2}$ QDs/TNRs film displays an enhanced visible-light absorption and a slight redshift of the absorption onset compared to the pure TNRs. Bulk $\mathrm{SnO}_{2}$ is a wide bandgap semiconductor [46], 
the spectrum redshift of the absorption spectrum may be attributed to the existence of $\mathrm{SnO}_{2}$ QDs $[50,74]$. There are a few possibilities may cause such a redshift: i) the changing of local refractive index (from air to $\mathrm{SnO}_{2}$ QDs) $[75,76]$; ii) the lattice distortion and surface pressure (resulted from the deposition of $\mathrm{SnO}_{2}$ QDs) [77, 78]; iii) the optical absorption redshift may also relate to the necking and electronic coupling from long-range ordered superstructures or core-shell-like structure, which can alter the exciton confinement energy after the nanocrystal's marginal lattice reconstruction (resulted from the deposition of $\mathrm{SnO}_{2}$ QDs) [79, 80].

The $\mathrm{rGO} / \mathrm{SnO}_{2}$ QDs/TNRs film shows an identical absorption onset to $\mathrm{SnO}_{2}$ QDs/TNRs which indicates that the deposition of rGO did not alter the electronic structure of the rutile $\mathrm{TiO}_{2}$ (carbon species are not doped into the lattice, for example). Moreover, compared with TNRs and $\mathrm{SnO}_{2} \mathrm{QDs} / \mathrm{TNRs}$, the $\mathrm{rGO} / \mathrm{SnO}_{2} \mathrm{QDs} / \mathrm{TNRs}$ film expands the broad background absorption into the visible light region, which is attributed to the unique visible light sensitization effect from rGO [81]. More importantly, due to the SPR effect from the Au-NPs, samples which contain Au-NPs have a notably enhanced light absorption in the wavelength ranging from 450 to 630 $\mathrm{nm}$. This result indicates that the Au-NPs can be used as an efficient visible-light sensitizer [82], which can enhance the light absorption of TNRs in the visible wavelength.

The PL analysis is a useful approach for determining the surface states, band trap states, as well as charge transfer dynamics in semiconductor materials and devices [83]. Fig. 4h displays the PL spectra of TNRs, $\mathrm{SnO}_{2}$ QDs/TNRs, $\mathrm{rGO} / \mathrm{SnO}_{2} \mathrm{QDs} / \mathrm{TNRs}$ and 
quaternary AGSQT NRs hybrid composite films excited by a light source with the 330 $\mathrm{nm}$ wavelength. For TNRs film, the peak at $410 \mathrm{~nm}$ is due to the phonon-assisted indirect transition from the edge $(\chi)$ to the centre $(I)$ of the Brillouin zone. In comparison, the peak at $438 \mathrm{~nm}$ is related to trapped $\mathrm{e}^{-}$recombined with $\mathrm{h}^{+}$inside the bulk lattice of $\mathrm{TiO}_{2}$. The peaks at 457,467 , and $484 \mathrm{~nm}$ are ascribed to the existence of oxygen vacancies in the TNRs [84]. The PL intensity decreases when the $\mathrm{SnO}_{2}$ QDs is deposited on the surface of TNRs, and it further reduces when the rGO layer covers onto the surface of the $\mathrm{SnO}_{2}$ QDs/TNRs film. Eventually, the lowest PL is obtained because of the formation of the quaternary composite film. Compared with pure TNRs, the reduced PL intensity of $\mathrm{SnO}_{2} \mathrm{QDs} / \mathrm{TNRs}$ is attributed to the formation of the typeII junction, which facilitates the disassociation of photogenerated excitons. Meanwhile, the $\mathrm{PL}$ intensity of $\mathrm{rGO} / \mathrm{SnO}_{2}$ QDs/TNRs film is slightly lower than that of $\mathrm{SnO}_{2}$ QDs/TNRs film, which indicates rGO can further facilitate the separation of $\mathrm{e}^{-} / \mathrm{h}^{+}$pairs. Furthermore, the PL intensity of the ternary composite film sharply decreases to the lowest value due to the deposition of Au-NPs onto the surface of the $\mathrm{rGO} / \mathrm{SnO}_{2}$ QDs/TNRs film. The band edge energy level (redox potential) difference between AuNPs, rGO, $\mathrm{SnO}_{2}$ and $\mathrm{TiO}_{2}$, allows the fast depletion of charge carriers along the stepwise band alignment, which results in the nearly quenched PL signals in quaternary composite films [85]. The broad visible light absorption of as-prepared quaternary AGSQT NRs hybrid composite film further indicates its potential to be used as a photoanode material in PCP application.

\subsection{Photoelectrochemical properties and photocathodic protection performances}


We carried out a systematically photoelectrochemical analysis to evaluate the PCP performance of as-prepared samples. A $500 \mathrm{~W}$ xenon lamp was employed as the light source, which is commonly used for simulating solar irradiation [86-88]. Fig. 5a displays a comparison result of the photoinduced current density among TNRs, $\mathrm{rGO} / \mathrm{SnO}_{2} \mathrm{QDs} / \mathrm{TNRs}, \mathrm{Au}-\mathrm{NPs} / \mathrm{SnO}_{2}$ QDs/TNRs, Au-NPs/rGO/TNRs and quaternary AGSQT NRs hybrid composite films. When the light source is switched on, the photocurrents densities of the samples are positive, which can be ascribed to the fact that the electrons immigrate from the photoanode to 304SS electrode. After switching off the light source, the photocurrents of all the samples dropped immediately because of the rapid recombination of $\mathrm{e}^{-} / \mathrm{h}^{+}$pairs [89]. Interestingly, we found the ranking of the photocurrent densities as a function of the coupled photoanodes is as follows: AGSQT NRs $\left(130 \mu \mathrm{A} \cdot \mathrm{cm}^{-2}\right)>\mathrm{Au}-\mathrm{NPs} / \mathrm{rGO} / \mathrm{TNRs}\left(120 \mu \mathrm{A} \cdot \mathrm{cm}^{-2}\right)>\mathrm{Au}-\mathrm{NPs} / \mathrm{SnO}_{2}$ QDs/TNRs $\left(80 \mu \mathrm{A} \cdot \mathrm{cm}^{-2}\right)>\mathrm{rGO} / \mathrm{SnO}_{2}$ QDs/TNRs $\left(30 \mu \mathrm{A} \cdot \mathrm{cm}^{-2}\right)>$ TNRs $\left(6 \mu \mathrm{A} \cdot \mathrm{cm}^{-2}\right)$. The hybrid composite film exhibits better photoelectrochemical performance than the pure TNRs film, which demonstrates that the hybridization of TNRs with other functional materials can enhance the visible-light conversion efficiency. Compared to $\mathrm{rGO} / \mathrm{SnO}_{2} \mathrm{QDs} / \mathrm{TNRs}$ film, the other three samples which contains Au-NPs show relatively higher photocurrent densities, which indicates Au-NPs can generate much more charge carriers associated with the SPR effect [25]. Besides, the photocurrent intensity of quaternary AGSQT NRs hybrid composite is much higher than that of Au-NPs/ $\mathrm{SnO}_{2}$ QDs/TNRs because of the presence of rGO. As a mediator layer in the composite film, rGO not only can enhance the visible light absorption but also can capture and transfer 'hot' 
electrons from 0D Au-NPs by way of its 2D $\pi$-conjugation structure [67]. Furthermore, the photocurrent of quaternary AGSQT NRs hybrid composite is also higher than that of Au-NPs/rGO/TNRs, which is because of the formation of $\mathrm{SnO}_{2} / \mathrm{TiO}_{2}$ type-II heterojunction [42]. This staggered band alignment can facilitate the charge carriers depletion and transport by way of the nanorods' unique 1D polarity [9].

To evaluate the cathodic protection performance for 304SS, pure TNRs film and composite films with a different combination $\left(\mathrm{rGO} / \mathrm{SnO}_{2}\right.$ QDs/TNRs, $\mathrm{Au}-\mathrm{NPs} / \mathrm{SnO}_{2}$ QDs/TNRs, Au-NPs/rGO/TNRs and AGSQT NRs films) were employed as photoanode electrodes. The protection effect is determined by analyzing the 304SS' surface potential changes under visible light illumination [90]. The OCP changes of 304SS in $3.5 \mathrm{wt} \% \mathrm{NaCl}$ solution are shown in Fig. 5b. Before being connected the circuit, the bare $304 \mathrm{SS}$ corrosion potential is about $-180 \mathrm{mV}$ vs $\mathrm{Ag} / \mathrm{AgCl}$. When 304SS is connected to the as-prepared films under dark condition, all as-measured potentials shift to a value lower than the corrosion potential of bare 304SS because of the galvanic effect [91]. When the visible light irradiation is provided, OCPs quickly decrease to more negative values, which are ascribed to the cathodic polarization of 304 SS resulting from the transfer of photoexcited electrons from the as-prepared photoanodes to 304SS. Afterwards, the OCP value maintains stable due to the established equilibrium. The value of as-measured potential can be ranked in an increasing series as: AGSQT NRs $(-840 \mathrm{mV}$ vs. $\mathrm{Ag} / \mathrm{AgCl})<\mathrm{Au}-\mathrm{NPs} / \mathrm{rGO} / \mathrm{TNRs}(-830 \mathrm{mV}$ vs. $\mathrm{Ag} / \mathrm{AgCl})<\mathrm{Au}-\mathrm{NPs} / \mathrm{SnO}_{2}$ QDs/TNRs (-700 mV vs. Ag/AgCl) $<$ rGO/SnO 2 QDs/TNRs $(-300 \mathrm{mV}$ vs. $\mathrm{Ag} / \mathrm{AgCl})<$ TNRs (-260 mV vs. $\mathrm{Ag} / \mathrm{AgCl})$. The more negative OCP value of the coupled steel, the 
better its cathodic protection performance [92, 93]. Taking account of the sequence of photocurrent intensity, we found the 0D-1D-2D multi-dimensional quaternary AGSQT NRs hybrid superstructure exhibits the best PCP performance for 304SS.

As shown in Fig. 5b, all the composite films display a better PCP effect than the TNRs film, suggesting that cathodic protection performance of TNRs film can be improved through forming heterojunction between $\mathrm{TiO}_{2}$ and other materials. In addition, we found all the OCP values of the 304SS coupled with composite films consisted of Au-NPs, are much more negative than the others. It indicates that the plasmon-excited 'hot' electrons in the Au-NPs can be transferred to the adjacent substrate and 304SS, which creates a more negative surface potential. Furthermore, through comparing the OCP values of 304SS connected with quaternary AGSQT NRs and Au-NPs/ $/ \mathrm{SnO}_{2}$ QDs/TNRs, we found the additional rGO in AGSQT NRs can serve as a collector of "hot-electrons" which facilitates electrons transfer from 0D Au-NPs to 1D TNRs [37]. Therefore, the recombination of $\mathrm{e}^{-} / \mathrm{h}^{+}$pairs is significantly suppressed, and more electrons can be injected to the coupled 304SS. Moreover, the photoresponse region of TNRs can be extended to the visible wavelength region due to the light sensitization effect from rGO layer [94].

Besides of $304 \mathrm{SS}$, carbon steel-such as $65 \mathrm{Mn}$ carbon steel (CS) was also connected to the as-prepared photoanodes to evaluate their anti-corrosion performance. As shown in Fig. S5, the OCP value of the 65Mn CS which is coupled with the with pure TNRs (-680 $\mathrm{mV}$ vs $\mathrm{Ag} / \mathrm{AgCl})$ or quaternary AGSQT NRs $(-910 \mathrm{mV}$ vs $\mathrm{Ag} / \mathrm{AgCl})$, is more negative than its natural corrosion potential (65Mn CS, $-616 \mathrm{mV}$ vs $\mathrm{Ag} / \mathrm{AgCl}$ ) [95]. 
These results indicate that the quaternary AGSQT NRs can also be used to protect carbon steels. Furthermore, as summarized in Table S2, our 0D-1D-2D multidimensional quaternary AGSQT NRs superstructure exhibited a better anti-corrosion efficiency than most of the previous reports.

It should be noted that the OCP values of $304 \mathrm{SS}$ coupled with quaternary AGSQT NRs and ternary Au-NPs/rGO/TNRs are nearly identical under visible light illumination. Nevertheless, after turning off the light source, during $500 \mathrm{~s}$, the OCP value of the quaternary AGSQT NRs $(-390 \mathrm{mV}$ vs $\mathrm{Ag} / \mathrm{AgCl})$ remains more negative than that of the $\mathrm{Au}-\mathrm{NPs} / \mathrm{rGO} / \mathrm{TNRs}(-280 \mathrm{mV}$ vs $\mathrm{Ag} / \mathrm{AgCl})$ as well as the corrosion potential of bare $304 \mathrm{SS}(-180 \mathrm{mV}$ vs $\mathrm{Ag} / \mathrm{AgCl})$. In principle, as described in the Equation (1), when the light source is turned on, excess electrons can be stored in the $0 \mathrm{D} \mathrm{SnO}_{2}$ QDs [44]. While cutting off the light, reverses reaction triggered and release the electrons which could transfer to the surface of 304SS to realize the cathodic protection $[46,96]$. Indeed, this is the critical step to achieving the time-delay protection for the steel after switching off the light $[44,97]$.

$$
\mathrm{SnO}_{2}+x e^{-}+x M^{+} \rightleftarrows M_{x} \mathrm{SnO}_{2} \quad(M=N a \text { or } \mathrm{H}, \mathrm{x}=1 \text { or } 2)
$$

To further understand the anti-corrosion process, Tafel curves of bare 304SS and 304SS connected with different photoanodes were collected with and without visible light irradiation. As shown in Fig. 5c, it can be seen that the corrosion potential of 304SS coupled with the as-prepared films exhibits remarkable potential shift (from -280 to $840 \mathrm{mV}$ vs $\mathrm{Ag} / \mathrm{AgCl})$ compared with that of bare 304SS (-187 mV vs $\mathrm{Ag} / \mathrm{AgCl})$ under illumination. The $\mathrm{E}_{\text {corr }}$ of $304 \mathrm{SS}$, coupled with quaternary AGSQT NRs film, exhibits 
the most negative value $(-840 \mathrm{mV}$ vs $\mathrm{Ag} / \mathrm{AgCl})$, which is in agreement with the OCP analysis results. Meanwhile, it is well-recognized that a high $\mathrm{j}_{\text {corr }}$ value can result in a better PCP performance under illumination [93]. Based on our Tafel curves, the $j_{\text {corr }}$ of AGSQT NRs/304SS $\left(141.25 \mu \mathrm{A} \cdot \mathrm{cm}^{-1}\right)$ is much higher than the other composite film/304SS $\left(13.87 \mu \mathrm{A} \cdot \mathrm{cm}^{-1}\right.$ to $\left.120.23 \mu \mathrm{A} \cdot \mathrm{cm}^{-1}\right)$ and bare 304SS $\left(0.47 \mu \mathrm{A} \cdot \mathrm{cm}^{-1}\right)$, which indicates an enhanced interfacial photoelectrochemical reaction associated to the polarisation of photogenerated charges. This result also suggests that the $0 \mathrm{D}-1 \mathrm{D}-2 \mathrm{D}$ multi-dimensional quaternary AGSQT NRs superstructure can provide more effective cathodic protection. Compared with bare 304SS, the dark $\mathrm{E}_{\text {corr }}$ of the $304 \mathrm{SS}$ (Fig. S6) change towards a more positive potential when coupled with modified photodiodes (to $-158 \mathrm{mV}$ with TNRs, $-126 \mathrm{mV}$ with $\mathrm{rGO} / \mathrm{SnO}_{2} \mathrm{QDs} / \mathrm{TNRs},-101 \mathrm{mv}$ with $\mathrm{Au}-\mathrm{NPs} / \mathrm{SnO}_{2}$ QDs/TNRs, $-80 \mathrm{mV}$ with Au-NPs/rGO/TNRs and -69 mV with AGSQT NRs, vs $\mathrm{Ag} / \mathrm{AgCl}$ ). Besides, the dark $\mathrm{j}_{\text {corr }}$ values of the 304SS connected with the TNRs, rGO/SnO ${ }_{2}$ QDs/TNRs, Au-NPs/SnO 2 QDs/TNRs, Au-NPs/rGO/TNRs and AGSQT NRs photoelectrodes are $0.32,0.13,0.09,0.11,0.06 \mu \mathrm{A} \cdot \mathrm{cm}^{-1}$, respectively, which are lower than that of the bare $304 \mathrm{SS}$. In the dark, the $\mathrm{j}_{\text {corr }}$ value is positively correlated with the corrosion rate of the steel [98]. Therefore, these results imply the multidimensional quaternary AGSQT NRs can also provide excellent anti-corrosion protection for the $304 \mathrm{SS}$ even in the dark condition.

EIS has been broadly used to study the corrosion mechanism between the corrosion solution and the metal because of its sensitivity and non-destructive characteristics [99]. Fig. 5d displays the Nyquist plots of the bare 304SS, and 304SS coupled with the as- 
prepared films (TNRs film, $\mathrm{rGO} / \mathrm{SnO}_{2}$ QDs/TNRs, $\mathrm{Au}-\mathrm{NPs} / \mathrm{SnO}_{2}$ QDs/TNRs, AuNPs/rGO/TNRs and quaternary AGSQT NRs hybrid composite films) under visible light radiation. The cathodic protection provided by the photoanode material exhibit different impedance characteristic from the traditional anti-corrosion coating approaches. Under visible light illumination, the electrons generated from the photoanode material immigrate to the protected 304SS, which results in a smaller impedance than the bare 304SS $[18,100]$. As shown in Fig. 5d, compared to the other electrodes, more photocurrent can be produced from the 0D-1D-2D multi-dimensional quaternary AGSQT NRs under visible light illumination, which leads to the smallest impedance.

The Bode plots in Fig. 5e shows that bare 304SS has one peak, whereas the others have two peaks. Therefore, bare 304SS electrode has one time constant, and 304SS coupled with as-prepared films, have two-time constants [98, 101]. Models of equivalent circuits for EIS results are displayed in Fig. 5f. $Q$ is a $C P E$ (constant phase element), which is used to replace the capacitance because the actual capacitance of solid electrodes is difficult to be measured in the electrochemical impedance analysis [102]. The admittance $Y$ and power index number $n$ define $C P E$ through the Equation $Y=Y_{0}(j \omega)^{n}$. In this Equation, $C P E$ is transformed into resistance $(n=0)$ or capacitance $(n=1)$. Generally, when $n$ is near to $1, C P E$ represents the capacitive properties of the interfaces. The equivalent circuit model of individual 304SS (Part I of Fig. 5f) can be described as $R_{S}\left(Q_{1} R_{c t}\right)$ [89]. More specifically, $R_{S}$ is solution resistance, $R_{c t}$ and $Q_{1}$ represent the charge transfer resistance and $C P E$, respectively. Since electrons 
immigrate from as-prepared electrodes to the surface of coupled 304SS, a layer of electrons is formed. Therefore, the equivalent circuit of 304SS coupled with the asprepared electrode (the part II of Fig. 5f) possesses two-time constants as $R_{S}\left(Q_{1} R_{f}\right)$ $\left(Q_{d l} R_{c t}\right)$ [101]. Particularly, $Q_{l}$ and $R_{f}$ from high frequencies represent the $C P E$ which corresponds to the electron layer, and passivation oxide film resistance, respectively. $C_{d l}$ and $R_{c t}$ at low frequencies stand for the double-layer capacitance and charge transfer resistance, respectively. The fitting results in Table S3 indicate that the 304SS connected to quaternary AGSQT NRs hybrid composite film displays the lowest $R_{c t}$ value compared with others. It means excess electrons can be generated from the 0D1D-2D multi-dimensional quaternary composite film under visible light illumination, and those charge carriers could be separated effectively and transferred rapidly to the connected 304SS, which could result in an improved high PCP performance [95]. The EIS results show that decorating Au-NPs, $\mathrm{rGO}$ and $\mathrm{SnO}_{2}$ QDs to TNRs films can improve charge transport and electron-hole pairs separation beyond either of the individual additives, which implies a synergistic effect between $\mathrm{Au}-\mathrm{NPs}, \mathrm{rGO}$ and $\mathrm{SnO}_{2}$ QDs in enhancing charge transfer in TNRs films.

\subsection{The stability evaluation of quaternary AGSQT NRs hybrid composite films}

As shown in Fig. 5g, the stability of quaternary AGSQT NRs hybrid composite during the PCP of $304 \mathrm{SS}$ is evaluated under long-period intermittently visible light irradiation. After being connected with composite films, the 304SS surface potential shifts negatively to around $-265 \mathrm{mV}$ vs $\mathrm{Ag} / \mathrm{AgCl}$ owing to the galvanic effect [91]. When visible light illumination is provided, the steel surface potential instantly dropped 
to $-845 \mathrm{mV}$ vs $\mathrm{Ag} / \mathrm{AgCl}$, which is consistent with the above photoelectrochemical analysis results. After turning off the light source ( $1 \mathrm{~h}$ visible light irradiation), the OCP value of the $304 \mathrm{SS}$, firstly, shift to $-370 \mathrm{mV}$ vs $\mathrm{Ag} / \mathrm{AgCl}$, then, the surface potential of 304SS which is coupled with a quaternary AGSQT NRs hybrid composite recover slowly (about $8.65 \mathrm{~h}$ ) back to the initial level. It suggests this composite film can maintain continuous protection even after cutting off the light. To estimate the potentialresponse stability of quaternary AGSQT NRs hybrid composite film in the PCP system, the changes of surface potential as a function of light intermission was investigated (as shown in the inset of Fig. 5g). The result demonstrates that the as-prepared film can provide long-lasting protection for 304SS under intermittent illumination. The OCP value (around $-400 \mathrm{mV}$ vs. $\mathrm{Ag} / \mathrm{AgCl}$ ) of $304 \mathrm{SS}$ remains negative than its initial potential (around $-270 \mathrm{mV}$ vs. $\mathrm{Ag} / \mathrm{AgCl}$ ) after intermittent 8 hours' visible light irradiation.

In order to study the long-term stability of the AGSQT NRs composite, a 12 hours' stability evaluation test was performed, which was continuously carried out on the first, fourth and seventh days. After turning on the light source, the OCPs of 304SS coupled with a quaternary composite response immediately and remain a steady status during the one-week stability test (Fig. S7), which confirms the robust PCP stability of asprepared AGSQT NRs.

Based on the above discussion, the unique multi-dimensional structure of the quaternary composite electrode can be considered as the main reason for the outstanding PCP performance for 304SS. Hence, it is crucial to assure the crystal 
structural stability of 0D-1D-2D multi-dimensional quaternary AGSQT NRs hybrid composite film after PCP experiment. As shown in Fig. 5h and Fig. 5i, SEM and TEM analysis confirmed that the 0D Au-NPs is still anchored on the rGO layer, and only a tiny number of Au-NPs have stripped off from the substrate. As a mediator layer, 2D rGO layer well remains, and their folds and wrinkles are still present after the stability evaluation experiments. Moreover, the morphology and crystal structure of $0 \mathrm{D} \mathrm{SnO}_{2}$ QDs on the surface of nanorods are consistent with the pristine samples, and the morphological changes of the 1D nano rod-like structure of TNRs are also negligible. The cross-section SEM image (Fig. S8a) of quaternary AGSQT NRs hybrid composite film further confirms negligible morphology alternation after 8 hours' PCP test. In addition, as shown in the XRD analysis of the quaternary AGSQT NRs hybrid composite before and after PCP experiment (Fig. S8b), no significant variation of the peak position and relative peak intensity can be detected. Furthermore, as shown in Fig. S8c and Fig. S8d, characteristic Raman peaks of this quaternary composite are also unchanged after 8 hours' PCP experiment.

In the cathodic protection system, the electrolyte $\left(\mathrm{S}^{2-}\right)$ of the photoelectrochemical cell plays a crucial role in scavenging $\mathrm{h}^{+}$(Equation (2)) for accelerating the separation of $\mathrm{e}^{-/ \mathrm{h}^{+}}$pairs [103]. However, there are concerns such as the reaction-generated elemental sulfur (S) may deposit onto the surface of the electrode to limit the charge transfer [100]. Fig. S9 displays the XPS survey spectrum of the quaternary composite film after PCP measurement. The characteristic Ti 2p, Sn 3d, Au 4f, O 1s and C 1s peaks can be observed, which confirms the compositional stability of the film. However, there 
is no peak from elemental $\mathrm{S}$ can be resolved, which suggests that the elemental $\mathrm{S}$ dissolve in the electrolyte solution is in the state of polysulfide ions (Equation (3) and (4)) [104]. Therefore, the elemental $\mathrm{S}$ generated by the oxidation reaction of $\mathrm{S}^{2-}$ does not exist on the surface of photoanode. Consequently, we believe it has a negligible effect on PCP performance.

$$
\begin{gathered}
S^{2-}+2 h^{+} \rightarrow S \\
(x-1) S+S^{2-} \rightarrow S_{x}^{2-}(x=2-5) \\
S+S_{x}^{2-} \rightarrow S_{x+1}^{2-}(x=2-4)
\end{gathered}
$$

The long-term adhesion of the composite material on the surface of the electrode is a highly important parameter for the practical industrial application. However, there is a lack of studies focused on adhesion stability. To this end, we carried out adhesion studies of the multi-dimensional quaternary hybrids on the FTO substrate based on the benchmark ASTM D 3359-09 protocols [105]. A cross-grating pattern was marked on this film, and adhesive tape was applied. Fig. S10a and Fig. S10b show the optical images of this coating before and after the tape test, and the result manifests that the adhesion stability of the coating layer is excellent. No distinct delamination or detachment of the film can be resolved; meanwhile, it should be noted that this test did not damage the coating even at the edge of the crosscut as shown in Fig S10c. According to the evaluation criterion given in the ASTM protocols, the coating adhesion stability of quaternary AGSQT NRs hybrid composite film could be evaluated as a perfect 5B. These results confirm that the quaternary composite coating can well adhere to the FTO glass. Furthermore, the transmittance spectroscopy was employed to quantitatively 
evaluate the adhesion strength between superstructure and substrate [106]. As shown in Fig. S10c, the transmittance variation of this composite film is just $4.3 \%$ (from $6.8 \%$ to $11.1 \%$ ) before and after tape test which further demonstrates the excellent physical adhesion strength of as-prepared quaternary AGSQT NRs hybrid composite film.

\subsection{DFT theoretical simulation}

As shown in Fig.6, the first-principle DFT calculation was performed to understand the total and partial electronic density of states (TDOS and PDOS) from as-prepared composite films. In pure TNRs (Fig. 6a), it is well-known that O $2 p$ state electrons dominate the valance band maximum (VBM) with a small contribution from Ti $3 \mathrm{~d}$ state electrons. In contrast, the primary contribution of $\mathrm{CB}$ minimum $(\mathrm{CBM})$ is $\mathrm{Ti} 3 \mathrm{~d}$ state electrons and involved a small amount of $\mathrm{O} 2 \mathrm{p}$ state electrons. Therefore, the bandgap of TNRs could be estimated through the energy difference between VBM and CBM. However, the calculated bandgap is smaller than the experimental value (ca. $3.0 \mathrm{eV}$ ), which is due to the commonly underestimated Hubbard interaction via the GGA theoretical calculation method [107]. When $\mathrm{SnO}_{2}$ QDs were deposited on the surface of nanorods (Fig. 6b), the bandgap of the binary composite film became smaller because of new electron states brought into the system. Sn $5 \mathrm{p}$ state electrons hybridize with $\mathrm{Ti}$ $3 \mathrm{~d}$, and $\mathrm{O} 2 \mathrm{p}$ states at upper valance band $(\mathrm{VB})$ region, which can further enhance the photoinduced carriers' mobility $[108,109]$. As listed in Table S4, the VBM position of TNRs film shifted positively after functionalizing with $\mathrm{SnO}_{2}$ QDs. Meanwhile, the valence band remains more or less the same, which is consistent with the trend shown in the DRS analysis (Fig. 4g). After deposition of rGO layer onto the $\mathrm{SnO}_{2} \mathrm{QDs} / \mathrm{TNRs}$ 
film, a new surface state appears in the bandgap at the bottom of the CB because of the appearance of C $2 \mathrm{p}$ states, which also mix with the $\mathrm{VB}$ edge of $\mathrm{rGO} / \mathrm{SnO}_{2} \mathrm{QDs} / \mathrm{TNRs}$ (Fig. 6c). Under these conditions, less energy is required for the photoelectron excitation from the band edge to the unoccupied states under light illumination. Meanwhile, the width of the VB is increased due to an extended mixing of orbitals, indicating the enhancement of the density of electrons [110]. As can be seen in Fig. 6d, after the formation of quaternary AGSQT NRs hybrid superstructure, there is a new set of peaks falling on the top of VB which are attributed to Au 5d states. Meanwhile, the presence of Au-NPs slightly reduces the bandgap of quaternary composite films compared to ternary $\mathrm{rGO} / \mathrm{SnO}_{2} \mathrm{QDs} / \mathrm{TNRs}$ films (as shown in Table S4). Moreover, the electronic hybridization state could also be improved between $\mathrm{Au} 5 \mathrm{~d}$ and the other bands. A high degree of hybridization in the $\mathrm{VB}$ and $\mathrm{CB}$ is better for photoelectrocatalysis reaction since it can promote the immigration of charge carriers [111]. Our DFT simulations are in agreement with the experimental results, which imply that the noble metal particles can enhance the PCP performance under visible light illumination associated with their SPR effect.

To study the mechanism of time-delay protection, the 3D charge-density-difference map of $\mathrm{SnO}_{2}$ QDs/TNRs film was reconstructed. As shown in Fig. 6e, charge density maps were reconstructed according to the following Equation:

$$
\Delta \rho=\rho_{\mathrm{SnO}_{2}-\mathrm{TiO}_{2}}-\left(\rho_{\mathrm{SnO}_{2}}+\rho_{\mathrm{TiO}_{2}}\right)
$$

where $\rho_{\mathrm{SnO}_{2}-\mathrm{TiO}_{2}}$ denoted the charge density of the monolithic $\mathrm{SnO}_{2} \mathrm{QDs} / \mathrm{TNRs}, \rho_{\mathrm{SnO}_{2}-}$ $\mathrm{TiO}_{2}$ and $\rho_{\mathrm{SnO}_{2}-\mathrm{TiO}_{2}}$ are the charge densities of the TNRs and $\mathrm{SnO}_{2} \mathrm{QDs}$, respectively [112, 
113]. As shown in Fig. $\mathrm{S} 11$, there are nine $\mathrm{O}$ atoms (green circles) from $\mathrm{TiO}_{2}$, which are connecting with $\mathrm{Sn}$ atoms in the binary composite film. Meanwhile, there are ten $\mathrm{Sn}$ atoms which are coupling with the $\mathrm{O}$ atoms (green circles) from $\mathrm{TiO}_{2}$. Also, the blue colour represents electronic depletion, while the yellow colour indicates the increase in charge density. As shown in Fig. 6e, the density of state redistribution occurs at the $\mathrm{SnO}_{2}$ QDs and the interface region of $\mathrm{SnO}_{2}$ QDs/TNRs heterojunction and several electron immigrations between $\mathrm{SnO}_{2}$ and $\mathrm{TiO}_{2}$. It is also clear that electrons predominantly transferred from the $\mathrm{O}$ atoms of $\mathrm{SnO}_{2} \mathrm{QDs}$ into the Ti atoms of TNRs, implying the formation of a polarized field in the $\mathrm{SnO}_{2}$ QDs/TNRs film, which could hinder the recombination of charge carriers and then improve PCP performance. More importantly, $\mathrm{SnO}_{2}$ QDs on the surface of nanorods act as electron storage for photogenerated charges. Stored electrons have the transfer tendency from $\mathrm{SnO}_{2}$ QDs to TNRs associated with its 1D electron transmission shortcut, which could achieve timedelay protection for 304SS. The charge transfer dynamics between $\mathrm{SnO}_{2}$ QDs and TNRs can be evaluated via using Bader charge analysis [112]. As shown in Table S5, the Bader charge values for the nine $\mathrm{O}$ atoms (as marked with green circles in Fig. S11) of $\mathrm{TiO}_{2}$ connecting with $\mathrm{Ti}$ atoms are in the ranges from $-1.060|\mathrm{e}|$ to $-1.120|\mathrm{e}|$. The Bader charge values for the $\mathrm{Sn}$ atoms coupled with the $\mathrm{O}$ atoms of $\mathrm{SnO}_{2}$ QDs are between $2.147|\mathrm{e}|$ to $2.247|\mathrm{e}|$, which are more prominent than those Sn atoms when the $\mathrm{SnO}_{2}$ QDs was calculated individually (1.690 |e| to $\left.1.769|\mathrm{e}|\right)$. These results clearly elucidate the charge transfer pathways between TNRs and $\mathrm{SnO}_{2}$ QDs under the dark condition. 


\subsection{Mechanism}

Mott-Schottky plot analysis was conducted to interpret the PCP mechanism. As shown in Fig. 7a, compared with pure TNRs film, the flat band potential of quaternary AGSQT NRs hybrid composite film shifts negatively, which is consistent with the above DFT calculations. This result manifests that the stepwise cascade band alignments between $\mathrm{TiO}_{2}, \mathrm{SnO}_{2}, \mathrm{rGO}$ and $\mathrm{Au}$ are successfully established in this quaternary composite film which hinders the $\mathrm{e}^{-} / \mathrm{h}^{+}$pairs recombination. As reported in previous works, there is a negative correlation between the slope of the Mott-Schottky plot and the charge density [114]. It can be seen that the slope of the curve for quaternary AGSQT NRs hybrid composite film is more negative than that of TNRs film, which confirms the high free charge density.

Meanwhile, the VB XPS spectra (Fig. 7b) suggests that the VB edge of TNRs and quaternary AGSQT NRs hybrid composite film are 2.65 and $2.07 \mathrm{eV}$, respectively. Combining with DRS results (Fig. 4g), the estimated CB positions are -0.35 and -0.81 eV for TNRs and quaternary AGSQT NRs hybrid composite film, respectively. Hence, the band edge alignment of CB is consistent with the above Mott-Schottky test, which indicates quaternary composite film could exhibit better PCP efficiency via hybridization of TNRs with Au-NPs, $\mathrm{rGO}$ and $\mathrm{SnO}_{2}$ QDs.

The proposed charge photogeneration and cathodic protection mechanism from asprepared quaternary AGSQT NRs hybrid superstructure were rationalized in Fig. 7c. The $\mathrm{CB}$ edge energy level of rutile- $\mathrm{TiO}_{2}\left(\mathrm{E}_{\mathrm{CB}}=-0.50 \mathrm{eV}\right)$ is more negative than that of $\mathrm{SnO}_{2} \mathrm{QDs}\left(\mathrm{E}_{\mathrm{CB}}=0 \mathrm{eV}\right)[50,115]$, and locates below the Fermi levels of rGO (-0.61 
eV) [37]. Meanwhile, the Fermi levels of Au-NPs is $0.50 \mathrm{eV}[116,117]$. When illuminated by visible light, the Au-NPs of the quaternary composite film captures the incident photons and then transforms the absorbed solar energy to free 'hot' electrons [29]. Since the energy levels of the SPR-generated electrons are above the work function of $\mathrm{Au}[28,118]$ and the Fermi levels of rGO [119], those 'hot' electrons can readily surpass the energy barrier and directly jump into the rGO mediator layer. Owing to the remarkable conductivity of graphene, the excited electrons captured by the $2 \mathrm{D}$ rGO layer rapidly flow into the CB of 1D TNRs, and then are transferred to the coupled 304SS. The visible light absorption of TNRs is enhanced associated to the sensitization effect from $\mathrm{rGO}$ and $\mathrm{SnO}_{2}$ QDs which provide additional electrons to the $304 \mathrm{SS}$. The $\mathrm{h}^{+}$located in the VB is consumed at the photoanode/electrolyte interface by oxidation reactions, which further improve the separation efficiency of $\mathrm{e}^{-} / \mathrm{h}^{+}$pairs. Hence, the charge transfer process in the photoanodes provides sufficient charges to keep 304SS in the cathodic polarization state, and thus suppress the steel corrosion effectively. Moreover, excess electrons are stored in the $\mathrm{SnO}_{2}$ QDs associated with the stepwise cascade band alignment, which does not affect the 1D electron transport pathway stems from TNRs. After cutting off the light, the temporarily stored electrons in $\mathrm{SnO}_{2}$ QDs can be released and transferred to the coupled 304SS, which provide the time-delay cathodic protection for the $304 \mathrm{SS}$ in the dark.

\section{Conclusion}

In conclusion, we propose a 0D-1D-2D multi-dimensional quaternary AGSQT NRs hybrid superstructure as a new platform for achieving material's full-time anti- 
corrosion protection. We synthesized the quaternary AGSQT NRs hybrid composite film by hydrothermal approach combined with in-situ impregnation, electrochemical deposition and solution thermal reduction. The quaternary composite film shows a remarkable $\mathrm{e}^{-} / \mathrm{h}^{+}$dissociation efficiency as well as superior photoelectrochemical performance. Exemplified from the $304 \mathrm{SS}$ and $65 \mathrm{Mn} \mathrm{CS}$, we demonstrate excellent cathodic protection under visible light irradiation from the as-prepared quaternary composite film. More importantly, owing to its "electron pool" effect from $\mathrm{SnO}_{2} \mathrm{QDs}$, we demonstrate that the quaternary composite film can provide continuous protection even without light illumination. Those results present an excellent synergistic effect from four kinds of materials with different dimensions, which exerts the unique role of each constituent towards high-performance PCP application. This distinctive quaternary composite superstructure is expected to provide a universal strategy for the future design of high-performance PCP materials.

\section{Acknowledgements}

The authors gratefully acknowledge the financial supports from the National Natural Science Foundation of China (Grant No. 21507104) and the financial support from Cardiff University.

\section{Reference}

[1] Y. Tsutsumi, A. Nishikata, T. Tsuru, Pitting corrosion mechanism of type 304 stainless steel under a droplet of chloride solutions, Corros. Sci. 49 (2007) 1394-1407.

[2] M.M. Momeni, M. Taghinejad, Y. Ghayeb, R. Bagheri, Z. Song, High-efficiency photoelectrochemical cathodic protection performance of the iron-nitrogen-sulfur-doped $\mathrm{TiO}_{2}$ 
nanotube as new efficient photoanodes, Mater. Res. Express 7 (2020) 086403.

[3] M. Levin, P. Wiklund, C. Leygraf, Bioorganic compounds as copper corrosion inhibitors in hydrocarbon media, Corros. Sci. 58 (2012) 104-114.

[4] M.R. Ortíz, M.A. Rodríguez, R.M. Carranza, Effect of crevice corrosion inhibitors on the passivity of alloy 22, J. Electrochem. Soc. 159 (2012) C469-C475.

[5] C. Arunchandran, S. Ramya, R.P. George, U. Kamachi Mudali, Self-healing corrosion resistive coatings based on inhibitor loaded $\mathrm{TiO}_{2}$ nanocontainers, J. Electrochem. Soc. 159 (2012) C552-C559.

[6] H.D. Johansen, C.M.A. Brett, A.J. Motheo, Corrosion protection of aluminium alloy by cerium conversion and conducting polymer duplex coatings, Corros. Sci. 63 (2012) 342-350.

[7] G. Kear, B.D. Barker, K.R. Stokes, F.C. Walsh, Corrosion and impressed current cathodic protection of copper-based materials using a bimetallic rotating cylinder electrode (BRCE), Corros. Sci. 47 (2005) 1694-1705.

[8] P. Refait, M. Jeannin, R. Sabot, H. Antony, S. Pineau, Corrosion and cathodic protection of carbon steel in the tidal zone: Products, mechanisms and kinetics, Corros. Sci. 90 (2015) 375-382.

[9] Y.P. Liu, C.C. Zhao, X. Wang, H. Xu, H. Wang, X.Y. Zhao, J.T. Feng, W. Yan, Z.J. Ren, Preparation of $\mathrm{PPy} / \mathrm{TiO}_{2}$ core-shell nanorods film and its photocathodic protection for 304 stainless steel under visible light, Mater. Res. Bull. 124 (2020) 110751.

[10] M.M. Momeni, S.H. Khansari-Zadeh, H. Farrokhpour, Fabrication of tungsten-iron-doped $\mathrm{TiO} 2$ nanotubes via anodization: new photoelectrodes for photoelectrochemical cathodic protection under visible light, SN Appl. Sci. 1 (2019) 1160.

[11] M.M. Momeni, Y. Ghayeb, M. Akbarnia, Z. Barati, Successive ionic layer adsorption and reaction (SILAR) deposition of nickel sulfide on the $\mathrm{Fe}_{2} \mathrm{O}_{3}$ nanotube for efficient photocathodic protection of stainless steel under visible light, J. Iran. Chem. Soc. (2020). DOI: 10.1007/s13738020-01992-1

[12] H.M. Xu, W. Liu, L.X. Cao, G. Su, R.J. Duan, Preparation of porous $\mathrm{TiO}_{2} / \mathrm{ZnO}$ composite film and its photocathodic protection properties for 304 stainless steel, Appl. Surf. Sci. 301 (2014) 508-514.

[13] M.M. Momeni, M. Taghinejad, Y. Ghayeb, R. Bagheri, Z. Song, Preparation of various boron-doped $\mathrm{TiO}_{2}$ nanostructures by in situ anodizing method and investigation of their photoelectrochemical and photocathodic protection properties, J. Iran. Chem. Soc. 16 (2019) 18391851.

[14] M.M. Momeni, M. Mahvari, Y. Ghayeb, Photoelectrochemical properties of iron-cobalt $\mathrm{WTiO}_{2}$ nanotube photoanodes for water splitting and photocathodic protection of stainless steel, $\mathrm{J}$. Electroanal. Chem. 832 (2019) 7-23.

[15] Y.F. Zhu, L. Xu, J. Hu, J. Zhang, R.G. Du, C.J. Lin, Fabrication of heterostructured $\mathrm{SrTiO}_{3} / \mathrm{TiO}_{2}$ nanotube array films and their use in photocathodic protection of stainless steel, Electrochim. Acta 121 (2014) 361-368.

[16] Y. Wang, J.G. Yu, W. Xiao, Q. Li, Microwave-assisted hydrothermal synthesis of graphene based $\mathrm{Au}-\mathrm{TiO}_{2}$ photocatalysts for efficient visible-light hydrogen production, J. Mater. Chem. A 2 (2014) 3847-3855.

[17] M.M. Momeni, Y. Ghayeb, N. Moosavi, Preparation of Ni-Pt/Fe- $-\mathrm{TiO}_{2}$ nanotube films for photoelectrochemical cathodic protection of 403 stainless steel, Nanotechnology 29 (2018) 425701.

[18] J. Hu, Z.C. Guan, Y. Liang, J.Z. Zhou, Q. Liu, H.P. Wang, H. Zhang, R.G. Du, Bi $2 \mathrm{~S}_{3}$ modified 
single crystalline rutile $\mathrm{TiO}_{2}$ nanorod array films for photoelectrochemical cathodic protection, Corros. Sci. 125 (2017) 59-67.

[19] N. Wei, Y. Liu, M. Feng, Z.X. Li, S.G. Chen, Y.B. Zheng, D.A. Wang, Controllable $\mathrm{TiO}_{2}$ core-shell phase heterojunction for efficient photoelectrochemical water splitting under solar light, Appl. Catal., B 244 (2019) 519-528.

[20] S.W. Cui, X.Y. Yin, Q.L. Yu, Y.P. Liu, D.A. Wang, F. Zhou, Polypyrrole nanowire/ $/ \mathrm{TiO}_{2}$ nanotube nanocomposites as photoanodes for photocathodic protection of Ti substrate and 304 stainless steel under visible light, Corros. Sci. 98 (2015) 471-477.

[21] M. Tian, G.S. Wu, A.C. Chen, Unique electrochemical catalytic behavior of Pt nanoparticles deposited on $\mathrm{TiO}_{2}$ nanotubes, ACS Catal. 2 (2012) 425-432.

[22] Y.H. Tang, S.L. Luo, Y.R. Teng, C.B. Liu, X.L. Xu, X.L. Zhang, L. Chen, Efficient removal of herbicide 2,4-dichlorophenoxyacetic acid from water using Ag/reduced graphene oxide codecorated $\mathrm{TiO}_{2}$ nanotube arrays, J Hazard Mater 241-242 (2012) 323-330.

[23] M. Altomare, N.T. Nguyen, S. Hejazi, P. Schmuki, A cocatalytic electron-transfer cascade site-selectively placed on $\mathrm{TiO}_{2}$ nanotubes yields enhanced photocatalytic $\mathrm{H}_{2}$ evolution, Adv. Funct. Mater. 28 (2018) 1704259.

[24] F. Mushtaq, A. Asani, M. Hoop, X.Z. Chen, S. Pané, Highly efficient coaxial TiO $2-\mathrm{PtPd}$ tubular nanomachines for photocatalytic water purification with multiple locomotion strategies, Adv Funct. Mater. 26 (2016) 6995-7002.

[25] Q.J. Shi, Z.J. Li, L. Chen, X.L. Zhang, W.H. Han, M.Z. Xie, J.L. Yang, L.Q. Jing, Synthesis of $\mathrm{SPR} \mathrm{Au} / \mathrm{BiVO}_{4}$ quantum dot/rutile- $\mathrm{TiO}_{2}$ nanorod array composites as efficient visible-light photocatalysts to convert $\mathrm{CO}_{2}$ and mechanism insight, Appl. Catal., B 244 (2019) 641-649.

[26] D.E. Willis, M.M. Taheri, O. Kizilkaya, T.R. Leite, L. Zhang, T. Ofoegbuna, K. Ding, J.A. Dorman, J.B. Baxter, K.M. McPeak, Critical coupling of visible light extends hot-electron lifetimes for $\mathrm{H}_{2} \mathrm{O}_{2}$ synthesis, ACS Appl. Mater. Interfaces 12 (2020) 22778-22788.

[27] J. Nelson, The Physics of Solar Cells. Imperial College Press, London, 2003.

[28] R. Boppella, S.T. Kochuveedu, H. Kim, M.J. Jeong, F. Marques Mota, J.H. Park, D.H. Kim, Plasmon-sensitized graphene $/ \mathrm{TiO}_{2}$ inverse opal nanostructures with enhanced charge collection efficiency for water splitting, ACS Appl. Mater. Interfaces 9 (2017) 7075-7083.

[29] W.H. Feng, B. Wang, Z.Y. Zheng, Z.B. Fang, Z.F. Wang, S.Y. Zhang, Y.H. Li, P. Liu, Predictive model for optimizing the near-field electromagnetic energy transfer in plasmonic nanostructure-involved photocatalysts, Appl. Catal., B 186 (2016) 143-150.

[30] G. Darabdhara, M.R. Das, Bimetallic Au-Pd nanoparticles on 2D supported graphitic carbon nitride and reduced graphene oxide sheets: A comparative photocatalytic degradation study of organic pollutants in water, Chemosphere 197 (2018) 817-829.

[31] R. Siavash Moakhar, G.K.L. Goh, A. Dolati, M. Ghorbani, Sunlight-driven photoelectrochemical sensor for direct determination of hexavalent chromium based on $\mathrm{Au}$ decorated rutile $\mathrm{TiO}_{2}$ nanorods, Appl. Catal., B 201 (2017) 411-418.

[32] Y.Z. Wang, M. Zu, S. Li, T. Butburee, L.Z. Wang, F. Peng, S.Q. Zhang, Dual modification of $\mathrm{TiO}_{2}$ nanorods for selective photoelectrochemical detection of organic compounds, Sens. Actuator B-Chem. 250 (2017) 307-314.

[33] B.S. Liu, J.Y. Wang, J.J. Yang, X.J. Zhao, Charge carrier interfacial transfer pathways from $\mathrm{TiO}_{2}$ and $\mathrm{Au} / \mathrm{TiO}_{2}$ nanorod arrays to electrolyte and the association with photocatalysis, Appl. Surf. Sci. 464 (2019) 367-375. 
[34] J. Luo, D.L. Li, Y. Yang, H.Q. Liu, J.Y. Chen, H.Y. Wang, Preparation of Au/reduced graphene oxide/hydrogenated $\mathrm{TiO}_{2}$ nanotube arrays ternary composites for visible-light-driven photoelectrochemical water splitting, J. Alloy. Compd. 661 (2016) 380-388.

[35] W. Tu, Y. Zhou, Q. Liu, S.C.Yan, S.S. Bao, X.Y. Wang, M. Xiao, Z.G. Zou, An in situ simultaneous reduction-hydrolysis technique for fabrication of $\mathrm{TiO}_{2}$-graphene $2 \mathrm{D}$ sandwich-like hybrid nanosheets: graphene-promoted selectivity of photocatalytic-driven hydrogenation and coupling of $\mathrm{CO}_{2}$ into methane and ethane, Adv. Funct. Mater. 23 (2013) 1743-1749.

[36] C. Chen, W.M. Cai, M.C. Long, B.X. Zhou, Y.H. Wu, D.Y. Wu, Y.J. Feng, Synthesis of visible-light responsive graphene oxide $/ \mathrm{TiO}_{2}$ composites with $\mathrm{p} / \mathrm{n}$ heterojunction, ACS Nano 4 (2010) 6425-6432.

[37] H. Li, Y.H. Li, M. Wang, Z. Niu, X.T. Wang, B.R. Hou, Preparation and photocathodic protection property of $\mathrm{ZnIn}_{2} \mathrm{~S}_{4} / \mathrm{RGO} / \mathrm{TiO}_{2}$ composites for Q235 carbon steel under visible light, Nanotechnology 29 (2018) 435706.

[38] G. Zerjav, M.S. Arshad, P. Djinovic, I. Junkar, J. Kovac, J. Zavasnik, A. Pintar, Improved electron-hole separation and migration in anatase $\mathrm{TiO}_{2}$ nanorod/reduced graphene oxide composites and their influence on photocatalytic performance, Nanoscale 9 (2017) 4578-4592.

[39] H. Li, X.T. Wang, L. Zhang, B.R. Hou, Preparation and photocathodic protection performance of CdSe/reduced graphene oxide/ $/ \mathrm{TiO}_{2}$ composite, Corros. Sci. 94 (2015) 342-349.

[40] J. Hu, Q. Liu, H. Zhang, C.D. Chen, Y. Liang, R.G. Du, C.J. Lin, Facile ultrasonic deposition of $\mathrm{SnO}_{2}$ nanoparticles on $\mathrm{TiO}_{2}$ nanotube films for enhanced photoelectrochemical performances, $\mathrm{J}$. Mater. Chem. A 3 (2015) 22605-22613.

[41] H.E. Cheng, C.Y. Lin, C.M. Hsu, Fabrication of $\mathrm{SnO}_{2}-\mathrm{TiO}_{2}$ core-shell nanopillar-array films for enhanced photocatalytic activity, Appl. Surf. Sci. 396 (2016) 393-399.

[42] T.H. Huy, D.P. Bui, F. Kang, Y.F. Wang, S.H. Liu, C.M. Thi, S.J. You, G.M. Chang, V.V. Pham, $\mathrm{SnO}_{2} / \mathrm{TiO}_{2}$ nanotube heterojunction: The first investigation of $\mathrm{NO}$ degradation by visible light-driven photocatalysis, Chemosphere 215 (2019) 323-332.

[43] B. Sun, Y.Z. Chen, L. Tao, H.B. Zhao, G.D. Zhou, Y.D. Xia, H.Y. Wang, Y. Zhao, Nanorods array of $\mathrm{SnO}_{2}$ quantum dots interspersed multiphase $\mathrm{TiO}_{2}$ heterojunctions with highly photocatalytic water splitting and self-rechargeable battery-like applications, ACS Appl. Mater. Interfaces 11 (2018) 2071-2081.

[44] J. Zhang, Z. Ur Rahman, Y. Zheng, C. Zhu, M. Tian, D. Wang, Nanoflower like $\mathrm{SnO}_{2}-\mathrm{TiO}_{2}$ nanotubes composite photoelectrode for efficient photocathodic protection of 304 stainless steel, Appl. Surf. Sci. 457 (2018) 516-521.

[45] J. Hu, Y.F. Zhu, Q. Liu, Y.B. Gao, R.G. Du, C.J. Lin, $\mathrm{SnO}_{2}$ nanoparticle films prepared by pulse current deposition for photocathodic protection of stainless steel, J. Electrochem. Soc. 162 (2015) C161-C166.

[46] J.T. Zhang, H.L. Yang, Y. Wang, X.H. Cui, Z. Wen, Y.P. Liu, L. Fan, J.T. Feng, Facile fabrication of $\mathrm{SnO}_{2}$ modified $\mathrm{TiO}_{2}$ nanorods film for efficient photocathodic protection of 304 stainless steel under simulated solar light, Corros. Sci. 176 (2020) 108927.

[47] M.J. Zhou, Z.O. Zeng, L. Zhong, Energy storage ability and anti-corrosion protection properties of $\mathrm{TiO}_{2}-\mathrm{SnO}_{2}$ system, Mater. Corros. 61 (2010) 324-327.

[48] H. Li, X.T. Wang, Y. Liu, B.R. Hou, $\mathrm{Ag}$ and $\mathrm{SnO}_{2}$ co-sensitized $\mathrm{TiO}_{2}$ photoanodes for protection of 304SS under visible light, Corros. Sci. 82 (2014) 145-153.

[49] B. Liu, E.S. Aydil, Growth of oriented single-crystalline rutile $\mathrm{TiO}_{2}$ nanorods on transparent 
conducting substrates for dye-sensitized solar cells, J. Am. Chem. Soc. 131 (2009) 3985-3990.

[50] Y.G. Zhang, Q. Lin, N. Tong, Z.Z. Zhang, H.Q. Zhuang, X.Y. Zhang, W. Ying, H.W. Zhang, X.X. Wang, Simple fabrication of $\mathrm{SnO}_{2}$ quantum-dot-modified $\mathrm{TiO}_{2}$ nanorod arrays with high photoelectrocatalytic activity for overall water splitting, Chemphyschem 19 (2018) 2717-2723.

[51] L. Girardi, S. Shuang, G.A. Rizzi, A. Sartorel, C. Marega, Z. Zhang, G. Granozzi, Visible light driven photoanodes for water oxidation based on novel $\mathrm{r}-\mathrm{GO} /$ beta- $-\mathrm{Cu}_{2} \mathrm{~V}_{2} \mathrm{O}_{7} / \mathrm{TiO}_{2}$ nanorods composites, Nanomaterials (Basel) 8 (2018) 544.

[52] X.Y. Li, X.Z. Du, Molybdenum disulfide nanosheets supported Au-Pd bimetallic nanoparticles for non-enzymatic electrochemical sensing of hydrogen peroxide and glucose, Sens. Actuators, B 239 (2017) 536-543.

[53] P. Soundarrajan, K. Sankarasubramanian, T. Logu, K. Sethuraman, K. Ramamurthi, Growth of rutile $\mathrm{TiO}_{2}$ nanorods on $\mathrm{TiO}_{2}$ seed layer prepared using facile low cost chemical methods, Mater. Lett. 116 (2014) 191-194.

[54] M.J. Mortelliti, A.N. Wang, J.L. Dempsey, Atomic layer deposition of $\mathrm{SnO}_{\mathrm{x}}$ onto mesoporous, nanocrsytalline $\mathrm{TiO}_{2}$ and $\mathrm{SnO}_{2}$ thin films, Polyhedron 171 (2019) 433-447.

[55] H. Li, J.Q. Chen, Z.B. Xia, J.H. Xing, Microwave-assisted preparation of self-doped $\mathrm{TiO}_{2}$ nanotube arrays for enhanced photoelectrochemical water splitting, J. Mater. Chem. A 3 (2015) 699705.

[56] Z. Zhang, J.H. Hao, W.S. Yang, B.P. Lu, X. Ke, B.L. Zhang, J.L. Tang, Porous $\mathrm{Co}_{3} \mathrm{O}_{4}$ nanorods-reduced graphene oxide with intrinsic peroxidase-like activity and catalysis in the degradation of methylene blue, ACS Appl. Mater. Interfaces 5 (2013) 3809-3815.

[57] Y. Zhang, W.Q. Cui, W.J. An, L. Liu, Y.H. Liang, Y.F. Zhu, Combination of photoelectrocatalysis and adsorption for removal of bisphenol A over $\mathrm{TiO}_{2}$-graphene hydrogel with 3D network structure, Appl. Catal., B 221 (2018) 36-46.

[58] T.V. Cuong, V.H. Pham, Q.T. Tran, J.S. Chung, E.W. Shin, J.S. Kim, E.J. Kim, Optoelectronic properties of graphene thin films prepared by thermal reduction of graphene oxide, Mater. Lett. 64 (2010) 765-767.

[59] H. Zhu, J. Tao, T. Wang, J. Deng, Growth of branched rutile $\mathrm{TiO}_{2}$ nanorod arrays on F-doped tin oxide substrate, Appl. Surf. Sci. 257 (2011) 10494-10498.

[60] D.J. Yang, I. Kamienchick, D.Y. Youn, A. Rothschild, I.D. Kim, Ultrasensitive and highly selective gas sensors based on electrospun $\mathrm{SnO}_{2}$ nanofibers modified by Pd loading, Adv. Funct. Mater. 20 (2010) 4258-4264.

[61] R. Rajagopal, K.S. Ryu, Synthesis of rGO-doped $\mathrm{Nb}_{4} \mathrm{O}_{5}-\mathrm{TiO}_{2}$ nanorods for photocatalytic and electrochemical energy storage applications, Appl. Catal., B 236 (2018) 125-139.

[62] C. Zhu, M. Shi, S.C. Yang, H. Zhang, Z.M. Yang, B.J. Ding, Growth of radial arranged $\mathrm{TiO}_{2}$ nanorods by direct oxidation of Al-coated In-738 superalloy, J. Alloy. Compd. 485 (2009) 328-332.

[63] B. Hou, D. Parker, G.P. Kissling, J.A. Jones, D. Cherns, D.J. Fermin, Structure and band edge energy of highly luminescent CdSei ${ }_{1-x} T_{x}$ alloyed quantum dots, J. Phys. Chem. C 117 (2013) 6814-6820.

[64] B. Hou, S.H. Jung, J. Zhang, Y. Hong, B.S. Kim, J.I. Sohn, E.K. Lee, B.L. Choi, D. Whang, S. Cha, J.M. Kim, Growth of quantum dot coated core-shell anisotropic nanowires for improved thermal and electronic transport, Appl. Phys. Lett. 114 (2019) 243104.

[65] A.D. McDonald, L.J. Perkins, A.R. Buller, Facile in vitro biocatalytic production of diverse tryptamines, Chembiochem 20 (2019) 1939-1944. 
[66] Z.J. Du, S.C. Zhang, T. Jiang, X.M. Wu, L. Zhang, H. Fang, Facile synthesis of $\mathrm{SnO}_{2}$ nanocrystals coated conducting polymer nanowires for enhanced lithium storage, J. Power Sources 219 (2012) 199-203.

[67] R.K. Biroju, B. Choudhury, P.K. Giri, Plasmon-enhanced strong visible light photocatalysis by defect engineered CVD graphene and graphene oxide physically functionalized with $\mathrm{Au}$ nanoparticles, Catal. Sci. Technol. 6 (2016) 7101-7112.

[68] C. Ying, H.Y. Gao, D.M. Wei, X.J. Dong, C. Yan, Langmuir-Blodgett assembly of visible light responsive $\mathrm{TiO}_{2}$ nanotube arrays/graphene oxide heterostructure, Appl. Surf. Sci. 392 (2016) 1036-1042.

[69] Y.P. Liu, W.L. Zhang, C.C. Zhao, H. Wang, J. Chen, L. Yang, J.T. Feng, W. Yan, Study on the synthesis of poly(pyrrole methane)s with the hydroxyl in different substituent position and their selective adsorption for $\mathrm{Pb}^{2+}$, Chem. Eng. J. 361 (2019) 528-537.

[70] W.Q. Cui, J. He, H. Wang, J.S. Hu, L. Liu, Y.H. Liang, Polyaniline hybridization promotes photo-electro-catalytic removal of organic contaminants over 3D network structure of rGHPANI/TiO 2 hydrogel, Appl. Catal., B 232 (2018) 232-245.

[71] J.N. Wang, G.R. Yang, J. Chen, Y.P. Liu, Y.K. Wang, C.Y. Lao, K. Xi, D.W. Yang, C.J. Harris, W. Yan, S.J. Ding, R.V. Kumar, Flexible and high-loading lithium-sulfur batteries enabled by integrated three-in-one fibrous membranes, Adv. Energy Mater. 9 (2019) 1902001.

[72] V. Marcelina, N. Syakir, S. Wyantuti, Y.W. Hartati, R. Hidayat, Fitrilawati, Characteristic of thermally reduced graphene oxide as supercapacitors electrode materials, IOP Conf. Ser.: Mater. Sci. Eng. 196 (2017) 012034.

[73] Z. Yu, D.T. Payne, L.P. Chi, H.H. Fielding, G. Thornton, Non-band-gap photoexcitation of hydroxylated $\mathrm{TiO}_{2}$, J. Phys. Chem. Lett. 6 (2015) 3391-3395.

[74] F. Du, X.Q. Zuo, Q. Yang, B. Yang, G. Li, Z.L. Ding, M.Z. Wu, Y.Q. Ma, S.W. Jin, K.R. Zhu, Facile assembly of $\mathrm{TiO}_{2}$ nanospheres/ $\mathrm{SnO}_{2}$ quantum dots composites with excellent photocatalyst activity for the degradation of methyl orange, Ceram. Int. 42 (2016) 12778-12782.

[75] J. Feng, Z.F. Wang, B. Shen, L.M. Zhang, X. Yang, N.Y. He, Effects of template removal on both morphology of mesoporous silica-coated gold nanorod and its biomedical application, RSC Adv. 4 (2014) 28683-28690.

[76] G. Oldfield, T. Ung, P. Mulvaney, $\mathrm{Au} @ \mathrm{SnO}_{2}$ Core-shell nanocapacitors, Adv. Mater. 12 (2000) 1519-1522.

[77] X.B. Chen, Y.B. Lou, A.C. Samia, C. Burda, Coherency strain effects on the optical response of core/shell heteronanostructures, Nano Lett. 3 (2003) 799-803.

[78] Y. Liu, P. Zhang, B.Z. Tian, J.L. Zhang, Core-shell structural CdS@ $\mathrm{SnO}_{2}$ nanorods with excellent visible-light photocatalytic activity for the selective oxidation of benzyl alcohol to benzaldehyde, ACS Appl. Mater. Interfaces 7 (2015) 13849-13858.

[79] Y.W. Cao, U. Banin, Growth and properties of semiconductor core/shell nanocrystals with InAs cores, J. Am. Chem. Soc. 122 (2000) 9692-9702.

[80] C.L. Wang, H. Zhang, J.H. Zhang, M.J. Li, H.Z. Sun, B. Yang, Application of ultrasonic irradiation in aqueous synthesis of highly fluorescent $\mathrm{CdTe} / \mathrm{CdS}$ core-shell nanocrystals, J. Phys. Chem. C 111 (2007) 2465-2469.

[81] L. Hui, Z.B. Xia, J.Q. Chen, L. Lei, J.H. Xing, Constructing ternary CdS/reduced graphene oxide $/ \mathrm{TiO}_{2}$ nanotube arrays hybrids for enhanced visible-light-driven photoelectrochemical and photocatalytic activity, Appl. Catal., B 168-169 (2015) 105-113. 
[82] S.Y. Xu, L.M. Guo, Q.J. Sun, Z.L. Wang, Piezotronic effect enhanced plasmonic photocatalysis by AuNPs/BaTiO 3 heterostructures, Adv. Funct. Mater. 29 (2019) 1808737.

[83] M. Meksi, A. Turki, H. Kochkar, L. Bousselmi, C. Guillard, G. Berhault, The role of lanthanum in the enhancement of photocatalytic properties of $\mathrm{TiO}_{2}$ nanomaterials obtained by calcination of hydrogenotitanate nanotubes, Appl. Catal., B 181 (2016) 651-660.

[84] N. Serpone, D. Lawless, R. Khairutdinov, Size effects on the photophysical properties of colloidal anatase $\mathrm{TiO}_{2}$ particles: Size quantization versus direct transitions in this indirect semiconductor?, J. Phys. Chem. 99 (1995) 16646-16654.

[85] M.A. Mohamed, J. Jaafar, M.F.M. Zain, L.J. Minggu, M.B. Kassim, M.S. Rosmi, N.H. Alias, N.A. Mohamad Nor, W.N.W. Salleh, M.H.D. Othman, In-depth understanding of core-shell nanoarchitecture evolution of g- $\mathrm{C}_{3} \mathrm{~N}_{4} @ \mathrm{C}, \mathrm{N}$ co-doped anatase/rutile: Efficient charge separation and enhanced visible-light photocatalytic performance, Appl. Surf. Sci. 436 (2018) 302-318.

[86] B.J. Finlayson-Pitts, J.N. Pitts, Chapter 16 - Applications of atmospheric chemistry: Air pollution control strategies and risk assessments for tropospheric ozone and associated photochemical oxidants, acids, particles, and hazardous air pollutants, in: B.J. Finlayson-Pitts, J.N. Pitts (Eds.) chemistry of the upper and lower atmosphere, Academic Press, San Diego, 2000, pp. 871-942.

[87] B. Hou, B.S. Kim, H.K.H. Lee, Y. Cho, P. Giraud, M. Liu, J. Zhang, M.L. Davies, J.R. Durrant, W.C. Tsoi, Z. Li, S.D. Dimitrov, J.I. Sohn, S. Cha, J.M. Kim, Multiphoton absorption stimulated metal chalcogenide quantum dot solar cells under ambient and concentrated irradiance, Adv. Funct. Mater. 30 (2020) 2004563.

[88] B. Hou, Y. Cho, B.S. Kim, J. Hong, J.B. Park, S.J. Ahn, J.I. Sohn, S. Cha, J.M. Kim, Highly monodispersed $\mathrm{PbS}$ quantum dots for outstanding cascaded-junction solar cells, ACS Energy Lett. 1 (2016) 834-839.

[89] X. Wang, Z.C. Guan, P. Jin, Y.Y. Tang, G.L. Song, G.K. Liu, R.G. Du, Facile fabrication of $\mathrm{BiVO}_{4}$ modified $\mathrm{TiO}_{2}$ nanotube film photoanode and its photocathodic protection effect on stainless steel, Corros. Sci. 157 (2019) 247-255.

[90] Y. Yang, Y.F. Cheng, One-step facile preparation of $\mathrm{ZnO}$ nanorods as high-performance photoanodes for photoelectrochemical cathodic protection, Electrochim. Acta 276 (2018) 311-318.

[91] P. Qiu, X.L. Sun, Y.Y. Lai, P.P. Gao, C.F. Chen, L. Ge, N-doped $\mathrm{TiO}_{2} @ \mathrm{TiO}_{2}$ visible light active film with stable and efficient photocathodic protection performance, J. Electroanal. Chem. 844 (2019) 91-98.

[92] T.T. Zhang, Y.P. Liu, J. Liang, D.A. Wang, Enhancement of photoelectrochemical and photocathodic protection properties of $\mathrm{TiO}_{2}$ nanotube arrays by simple surface UV treatment, Appl. Surf. Sci. 394 (2017) 440-445

[93] Z.Q. Lin, Y.K. Lai, R.G. Hu, J. Li, R.G. Du, C.J. Lin, A highly efficient ZnS/CdS@ $\mathrm{TiO}_{2}$ photoelectrode for photogenerated cathodic protection of metals, Electrochim. Acta 55 (2010) 87178723.

[94] W.J. Liu, T. Du, Q.X. Ru, S.X. Zuo, Y.H. Cai, C. Yao, Preparation of graphene/ $/ \mathrm{WO}_{3} / \mathrm{TiO}_{2}$ composite and its photocathodic protection performance for 304 stainless steel, Mater. Res. Bull. 102 (2018) 399-405.

[95] D.W. Xu, Y. Liu, Y.H. Zhang, Z.Y. Shi, M.K. Yang, C. Zhang, B. Liu, Fabrication of pyramid$\mathrm{BiVO}_{4} / \mathrm{CdSe}$ composite with controlled surface oxygen vacancies boosting efficient carriers' separation for photocathodic protection, Chem. Eng. J. 393 (2020) 124693. 
[96] W.H. Cheng, C.D. Li, X. Ma, L.M. Yu, G.Y. Liu, Effect of $\mathrm{SiO}_{2}$-doping on photogenerated cathodic protection of nano- $\mathrm{TiO}_{2}$ films on 304 stainless steel, Mater. Des. 126 (2017) 155-161.

[97] W.J. Liu, K.C. Yin, F. He, Q.X. Ru, S.X. Zuo, C. Yao, A highly efficient reduced graphene oxide $/ \mathrm{SnO}_{2} / \mathrm{TiO}_{2}$ composite as photoanode for photocathodic protection of 304 stainless steel, Mater. Res. Bull. 113 (2019) 6-13.

[98] W.X. Sun, N. Wei, H.Z. Cui, Y. Lin, X.Z. Wang, J. Tian, J. Li, J. Wen, 3D ZnIn ${ }_{2} \mathrm{~S}_{4}$ nanosheet $/ \mathrm{TiO}_{2}$ nanowire arrays and their efficient photocathodic protection for 304 stainless steel, Appl. Surf. Sci. 434 (2018) 1030-1039.

[99] J. Zhang, J. Hu, Y.F. Zhu, Q. Liu, H. Zhang, R.G. Du, C.J. Lin, Fabrication of CdTe/ZnS core/shell quantum dots sensitized $\mathrm{TiO}_{2}$ nanotube films for photocathodic protection of stainless steel, Corros. Sci. 99 (2015) 118-124.

[100] J.F. Ren, B. Qian, J.Z. Li, Z.W. Song, L. Hao, J.S. Shi, Highly efficient polypyrrole sensitized $\mathrm{TiO}_{2}$ nanotube films for photocathodic protection of Q235 carbon steel, Corros. Sci. 111 (2016) 596-601.

[101] W.X. Sun, S.W. Cui, N. Wei, S.G. Chen, Y.P. Liu, D.A. Wang, Hierarchical $\mathrm{WO}_{3} / \mathrm{TiO}_{2}$ nanotube nanocomposites for efficient photocathodic protection of 304 stainless steel under visible light, J. Alloy. Compd. 749 (2018) 741-749.

[102] R.M. Fernández-Domene, R. Sánchez-Tovar, B. Lucas-granados, M.J. Muñoz-Portero, J. García-Antón, Elimination of pesticide atrazine by photoelectrocatalysis using a photoanode based on $\mathrm{WO}_{3}$ nanosheets, Chem. Eng. J. 350 (2018) 1114-1124.

[103] Z.C. Guan, X. Wang, P. Jin, Y.Y. Tang, H.P. Wang, G.L. Song, R.G. Du, Enhanced photoelectrochemical performances of $\mathrm{ZnS}-\mathrm{Bi}_{2} \mathrm{~S}_{3} / \mathrm{TiO}_{2} / \mathrm{WO}_{3}$ composite film for photocathodic protection, Corros. Sci. 143 (2018) 31-38.

[104] A.A. Anani, Z. Mao, R.E. White, S. Srinivasan, A.J. Appleby, ChemInform abstract: Electrochemical production of hydrogen and sulfur by low-temperature decomposition of hydrogen sulfide in an aqueous alkaline solution, Cheminform 21 (1990) 2703-2709.

[105] S.C. Vanithakumari, R.P. George, U. Kamachi Mudali, Environmental stability and longterm durability of superhydrophobic coatings on titanium, J. Mater. Eng. Perform. 26 (2017) 26402648.

[106] D.Y. Lee, J.T. Kim, Y.H. Kim, I.K. Lee, M.H. Lee, B.Y, Kim, Bond Strength of $\mathrm{TiO}_{2}$ Coatings onto FTO Glass for a Dye-sensitized Solar Cell, J. Sens. Sci. Technol. 21 (2012) 395-401.

[107] X. Tong, W.H. Shen, X.Q. Chen, Enhanced $\mathrm{H}_{2} \mathrm{~S}$ sensing performance of cobalt doped freestanding $\mathrm{TiO}_{2}$ nanotube array film and theoretical simulation based on density functional theory, Appl. Surf. Sci. 469 (2019) 414-422.

[108] A. Iwaszuk, M. Nolan, SnO-nanocluster modified anatase $\mathrm{TiO}_{2}$ photocatalyst: exploiting the $\mathrm{Sn}(\mathrm{II})$ lone pair for a new photocatalyst material with visible light absorption and charge carrier separation, J. Mater. Chem. A 1 (2013) 6670-6677.

[109] A. Walsh, D.J. Payne, R.G. Egdell, G.W. Watson, Stereochemistry of post-transition metal oxides: revision of the classical lone pair model, Chem. Soc. Rev. 40 (2011) 4455-4463.

[110] Y.A. Sethi, C.S. Praveen, R.P. Panmand, A. Ambalkar, A.K. Kulkarni, S.W. Gosavi, M.V. Kulkarni, B.B. Kale, Perforated N-doped monoclinic $\mathrm{ZnWO}_{4}$ nanorods for efficient photocatalytic hydrogen generation and RhB degradation under natural sunlight, Catal. Sci. Technol. 8 (2018) 2909-2919.

[111] S.J. Wang, F.T. He, X.L. Zhao, J.Q. Zhang, Z.M. Ao, H. Wu, Y. Yin, L. Shi, X.Y. Xu, C.C. 
Zhao, S.B. Wang, H.Q. Sun, Phosphorous doped carbon nitride nanobelts for photodegradation of emerging contaminants and hydrogen evolution, Appl. Catal., B 257 (2019) 117931.

[112] Y. Meng, J.J. Zhang, Z.Z. Wang, J.X. Liang, C. Zhu, Theoretical investigation on the photoelectrochemical anticorrosion mechanism of $\mathrm{SnO}_{2}-\mathrm{TiO}_{2}$ nanotube, J. Theor. Comput. Chem. 18 (2019) 1950016-1950026.

[113] H.T. Gao, J. Jia, F.J. Guo, B.J. Lin, D.M. Dai, X.Y. Deng, X. Liu, C.D. Si, G.J. Liu, The electronic structure and photoactivity of $\mathrm{TiO}_{2}$ modified by hybridization with monolayer $\mathrm{g}-\mathrm{C}_{3} \mathrm{~N}_{4}, \mathrm{~J}$. Photochem. Photobiol., A 364 (2018) 328-335.

[114] X.T. Wang, J. Lei, Q. Shao, X.R. Li, X.B. Ning, J. Shao, J.Z. Duan, B.R. Hou, Preparation of $\mathrm{ZnWO}_{4} / \mathrm{TiO}_{2}$ composite film and its photocathodic protection for 304 stainless steel under visible light, Nanotechnology 30 (2018) 045710.

[115] K. Vinodgopal, P.V. Kamat, Enhanced rates of photocatalytic degradation of an azo dye using $\mathrm{SnO}_{2} / \mathrm{TiO}_{2}$ coupled semiconductor thin films, Environ. Sci. Technol. 29 (1995) 841-845.

[116] V. Subramanian, E.E. Wolf, P.V. Kamat, Catalysis with $\mathrm{TiO}_{2} /$ gold nanocomposites. Effect of metal particle size on the fermi level equilibration, J. Am. Chem. Soc. 126 (2004) 4943-4950.

[117] F. Lin, B. Shao, Z. Li, J.Y. Zhang, H. Wang, S.H. Zhang, M. Haruta, J.H. Huang, Visible light photocatalysis over solid acid: Enhanced by gold plasmonic effect, Appl. Catal., B 218 (2017) 480-487.

[118] I. Campillo, J.M. Pitarke, A. Rubio, P.M. Echenique, The role of occupied d states in the relaxation of hot electrons in Au, Phys. Rev. B: Condens. Matter Mater. Phys. 62 (2000) 1500-1503.

[119] J. Wang, F.J. Trindade, C.B. de Aquino, J.C. Pieretti, S.H. Domingues, R.A. Ando, P.H. Camargo, Probing the catalytic activity of reduced graphene oxide decorated with Au nanoparticles triggered by visible light, Chem. - Eur. J. 21 (2015) 9889-9894. 


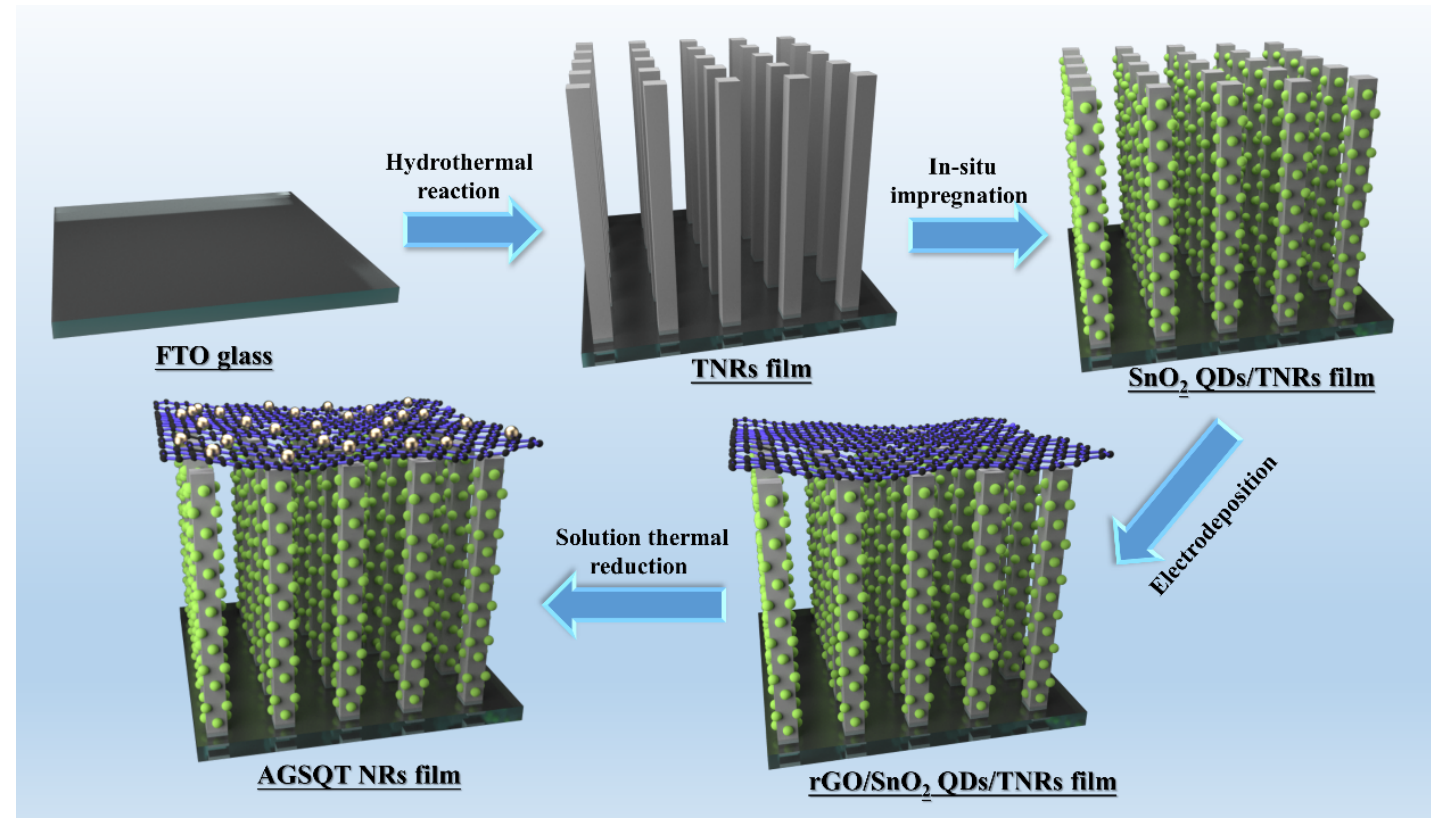

Scheme 1. Schematic illustration of the synthesis process for the quaternary AGSQT NRs hybrid composite film. 

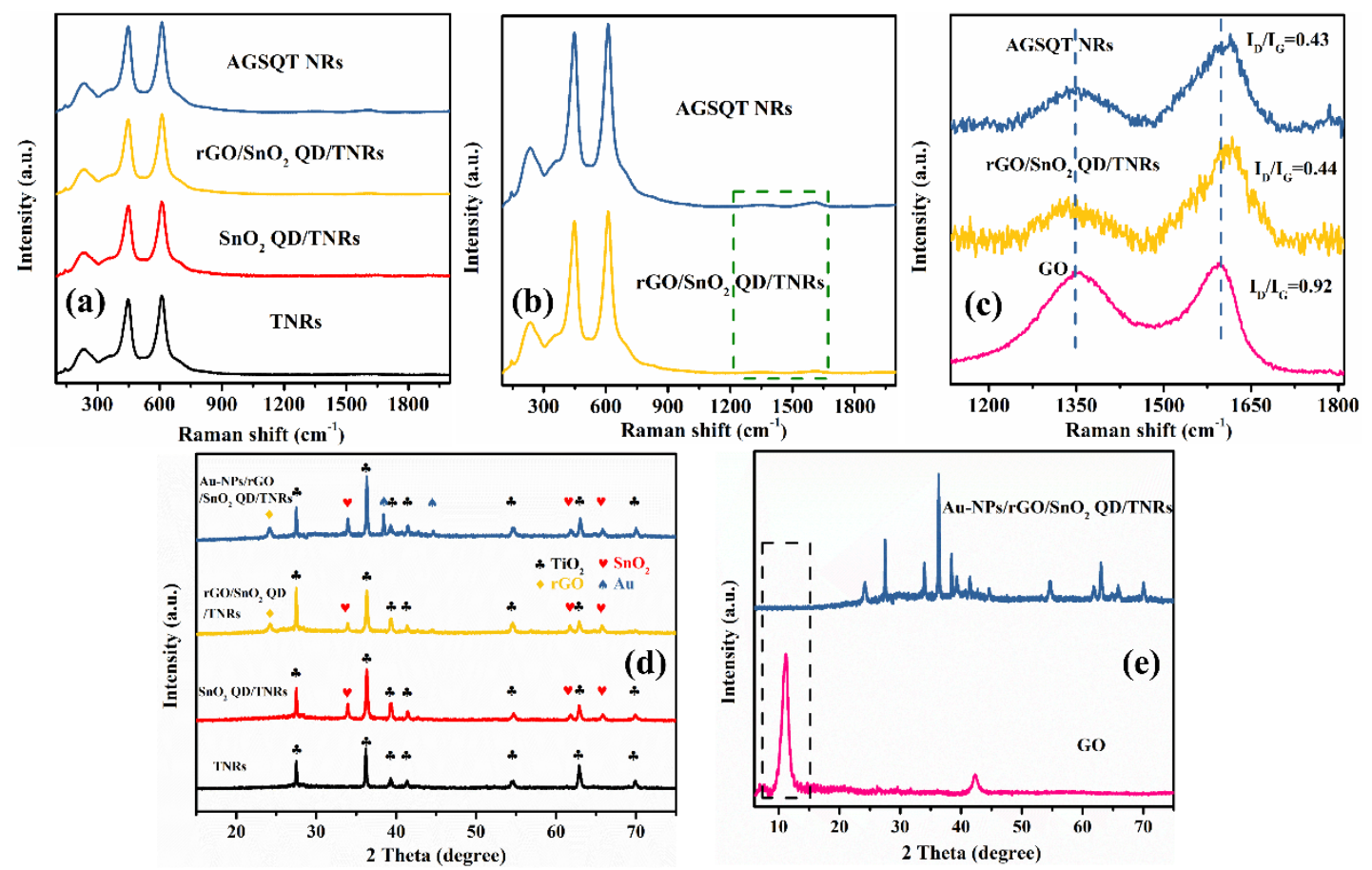

Fig. 1. (a) The Raman spectra of hybrid AGSQT NRs and each component. (b, c) Enlarged Raman spectra to highlight the presence of Au-NPs (b) and rGO (c). (d) The XRD patterns of hybrid AGSQT NRs and each component. (e) Enlarged XRD diffractograms to highlight the presence of rGO. 

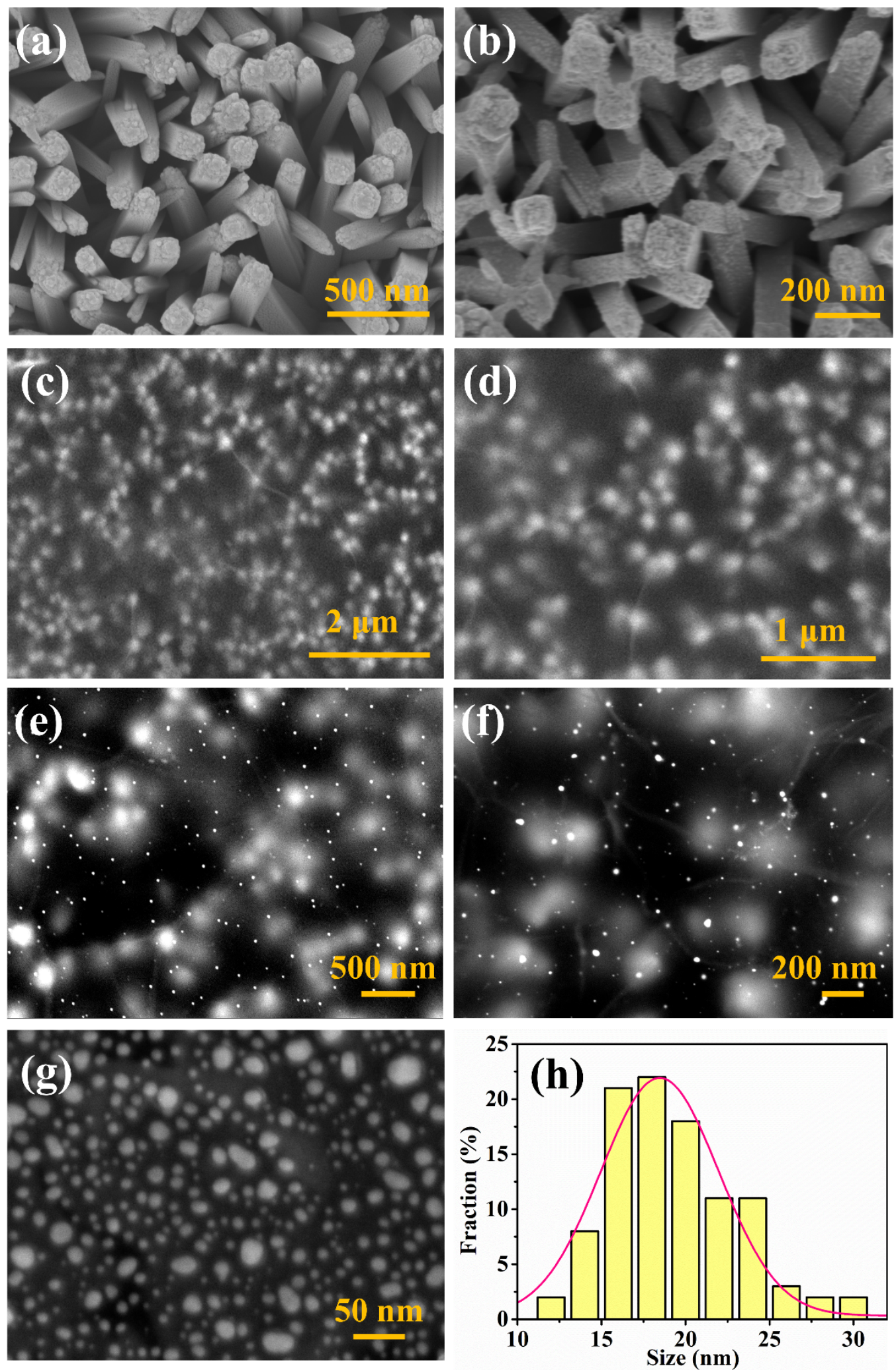

Fig. 2. Top-view SEM images of the TNRs (a), $\mathrm{SnO}_{2} \mathrm{QDs} / \mathrm{TNRs}$ (b), $\mathrm{rGO} / \mathrm{SnO}_{2} \mathrm{QDs} / \mathrm{TNRs}$ (c and d) and AGSQT NRs (e, f and g) films. (h) The size distribution of Au-NPs in quaternary AGSQT NRs hybrid composite film. 

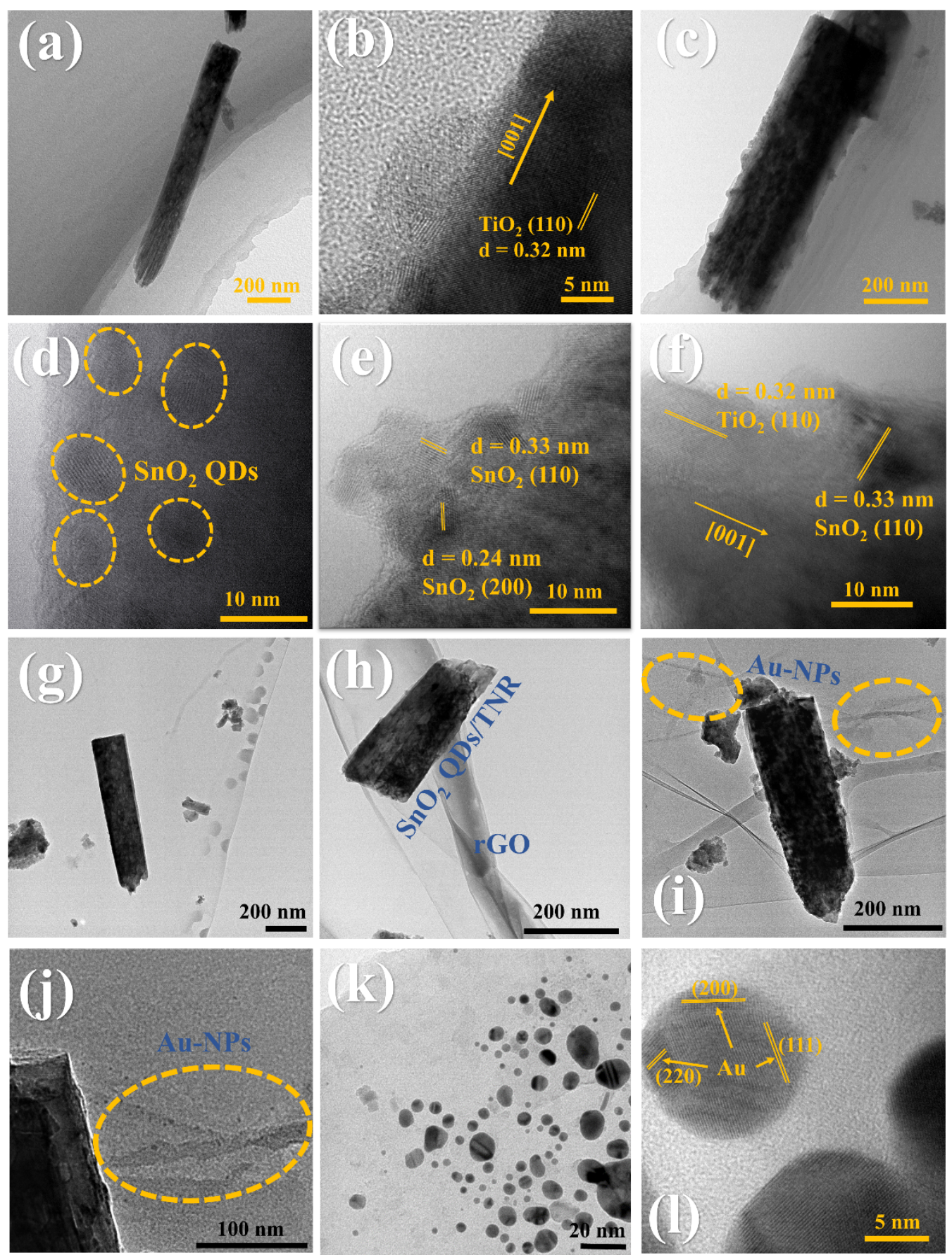

Fig. 3. TEM images of TNRs (a), $\mathrm{SnO}_{2}$ QDs/TNRs (c), $\mathrm{rGO} / \mathrm{SnO}_{2} \mathrm{QDs} / \mathrm{TNRs}$ ( $\mathrm{g}$ and $\mathrm{h}$ ) and AGSQT NRs ( $i$ and $j$ ). HRTEM images to show the detail microstructure information of TNRs (b), $\mathrm{SnO}_{2} \mathrm{QDs} / \mathrm{TNRs}$ (d, e and $\mathrm{f}$ ), and Au-NRs in AGSQT NRs ( $\mathrm{k}$ and l). 

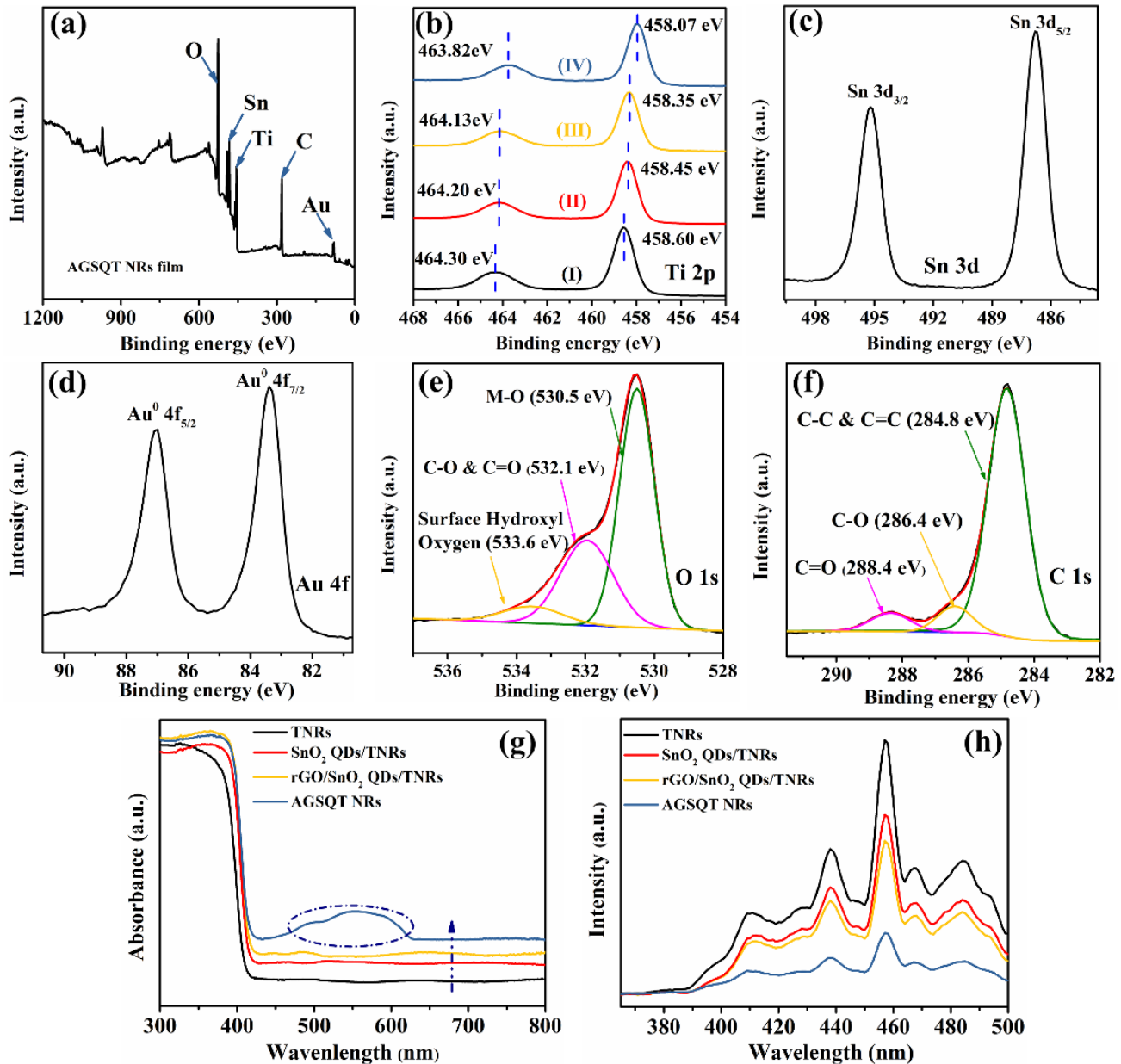

Fig. 4. Full scan survey XPS spectrum (a) and exemplified XPS spectra of Ti 2p (b), Sn 3d (c), Au $4 \mathrm{f}(\mathrm{d}), \mathrm{O} 1 \mathrm{~s}$ (e) and C 1s (f) from quaternary AGSQT NRs hybrid composite. A comparison of Ti $2 \mathrm{p}$ XPS spectrum between different samples (TNRs (I), $\mathrm{SnO}_{2}$ QDs/TNRs (II), $\mathrm{rGO} / \mathrm{SnO}_{2}$

QDs/TNRs (III) and AGSQT NRs (IV)) is also listed in (b). DRS (g) and PL spectra (h) of quaternary AGSQT NRs hybrid composite films and each component. 

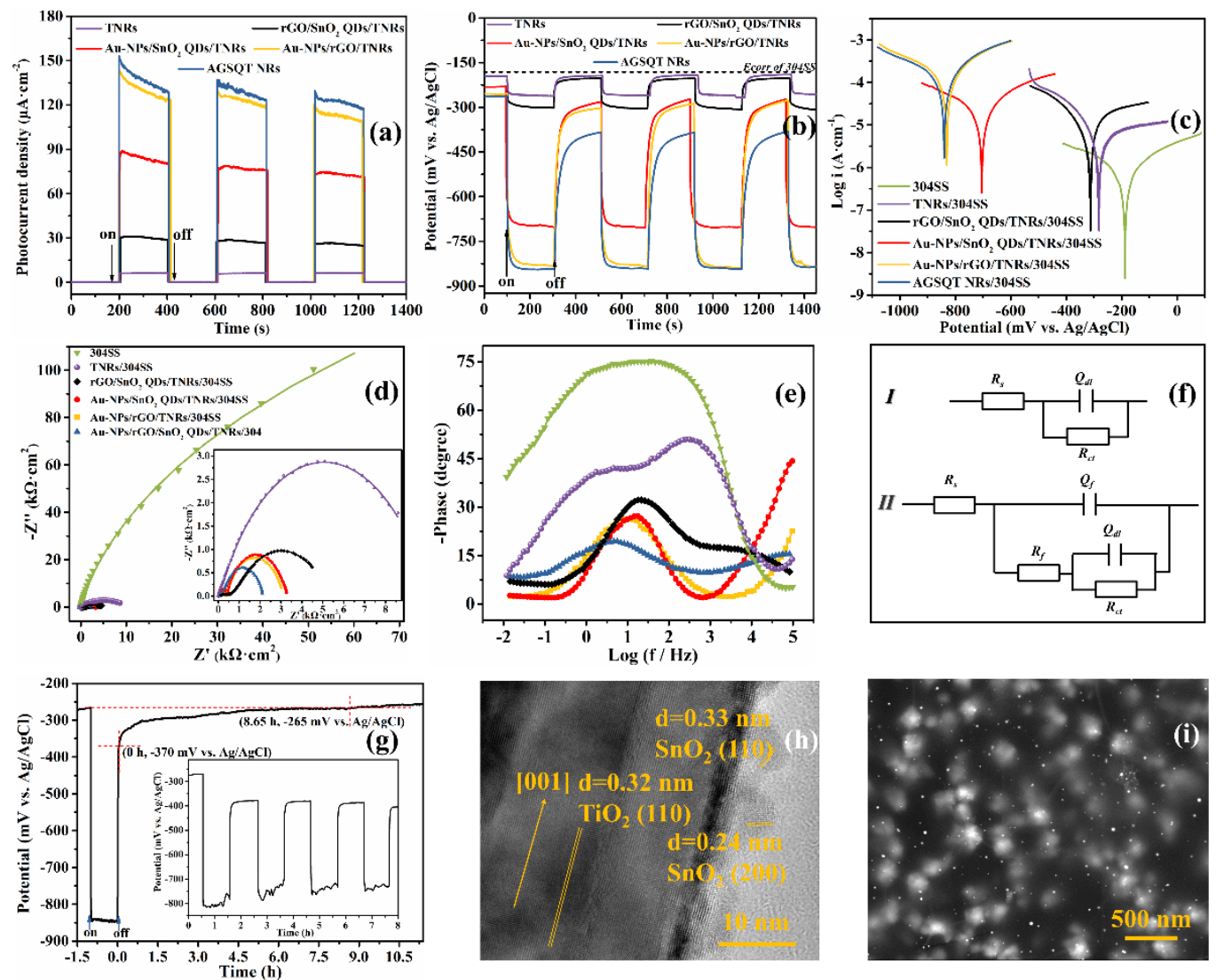

Fig. 5. (a) The photocurrent responses between the as-prepared samples and 304SS electrode under intermittent visible-light irradiation. (b) Potential variations, (c) polarization curves, (d) Nyquist plots, and (e) Bode-Phase plots of bare 304SS, and 304SS coupled with AGSQT NRs and each component under intermittent visible-light irradiation. (f) The equivalent circuit for fitting the impedance data. (g) The time-resolved potential evolution of 304SS coupled with AGSQT NRs hybrid composite film after photoexcitation. The inset shows the potential curves of 304SS coupled with this composite film to the light on/off cycles. The HRTEM (h) and SEM (i) images of the AGSQT NRs film after 8 hours' intermittently visible light illumination. 

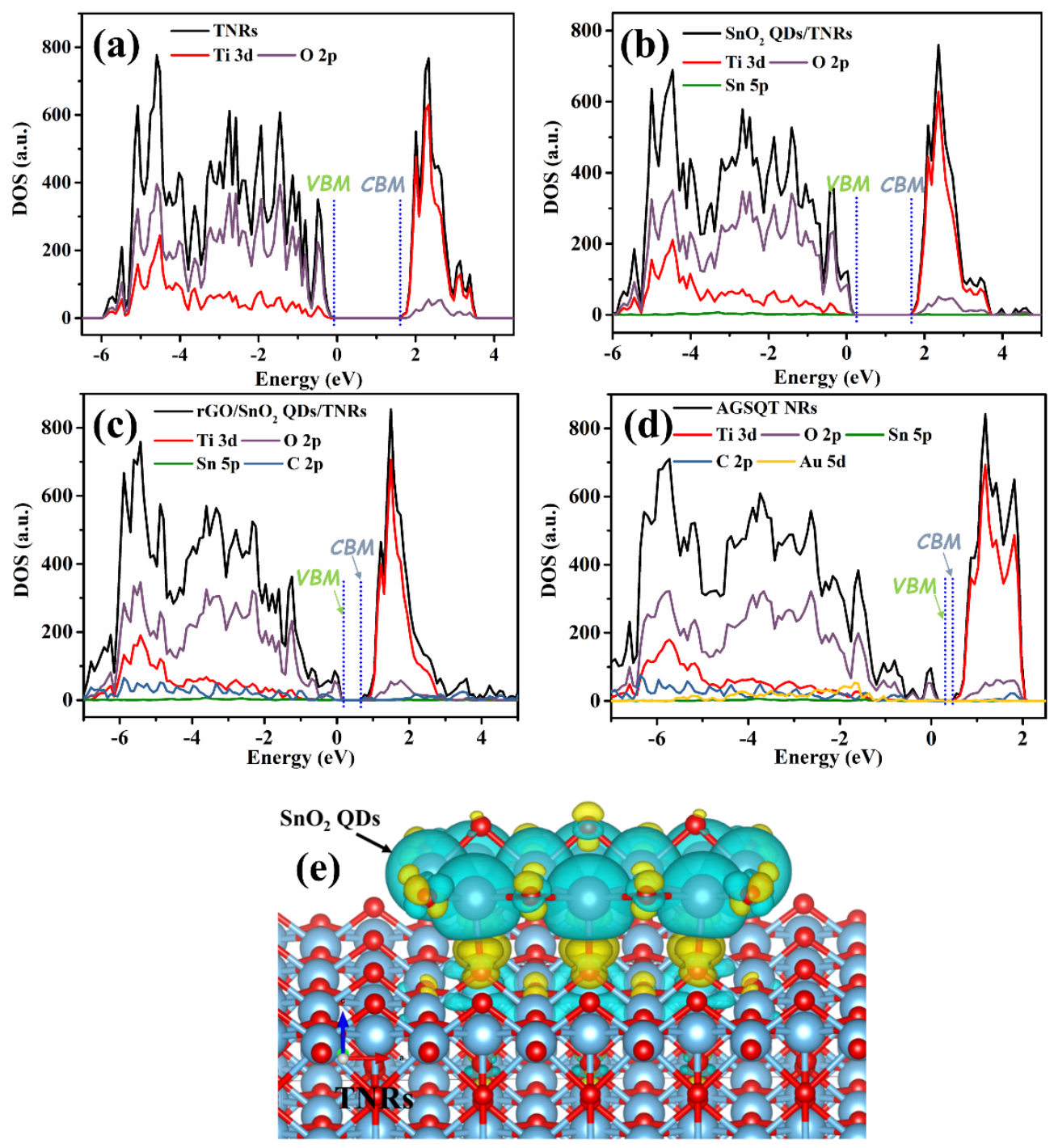

Fig. 6. Total and partial electronic density of states (TDOS and PDOS) for individual components (a-c) and AGSQT NRs hybrids (d). (e) The bird's view of 3D charge density differences of $\mathrm{SnO}_{2}$ QDs/TNRs film with an isovalue of $0.005 \mathrm{e} \cdot \AA^{-3}$ (red, blue and violet balls refer to O, Ti and Sn atoms, respectively). 

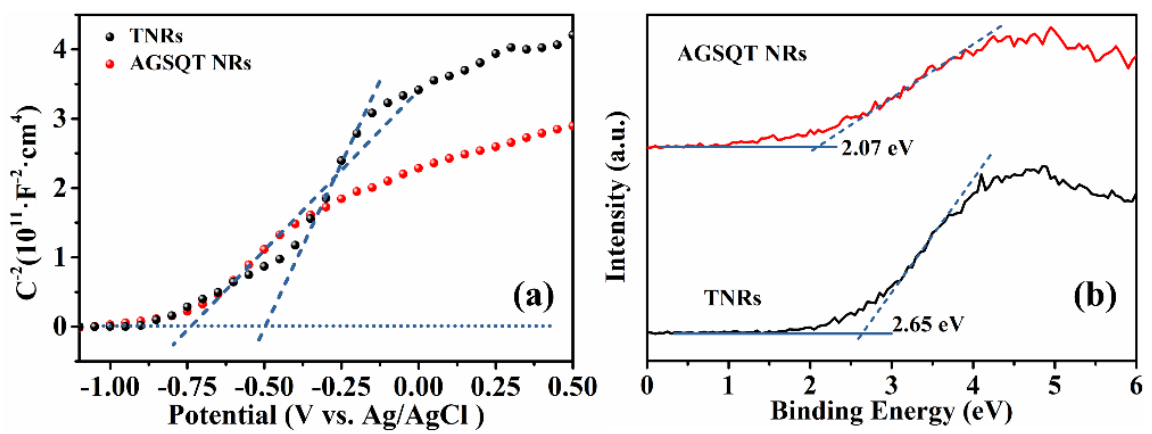

(c)
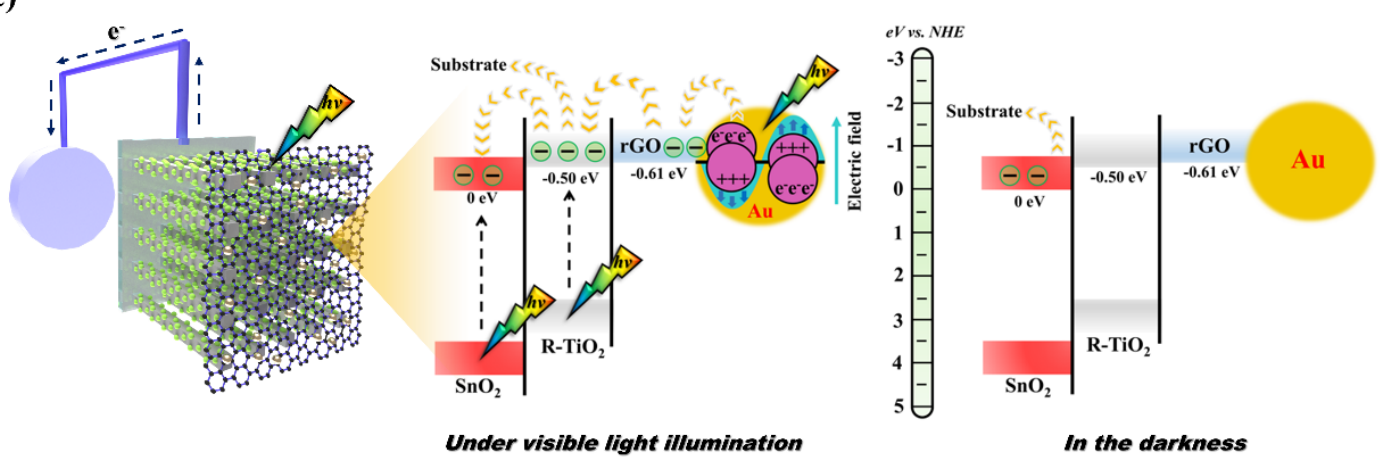

Fig. 7. Mott-Schottky plots (a) and VB XPS spectra (b) of TNRs and AGSQT NRs films. (c) The schematic and energy level alignment for illustrating the as-proposed charge photogeneration and transfer mechanism in the AGSQT NRs film enhanced PCP application. 


\section{Table of Contents}

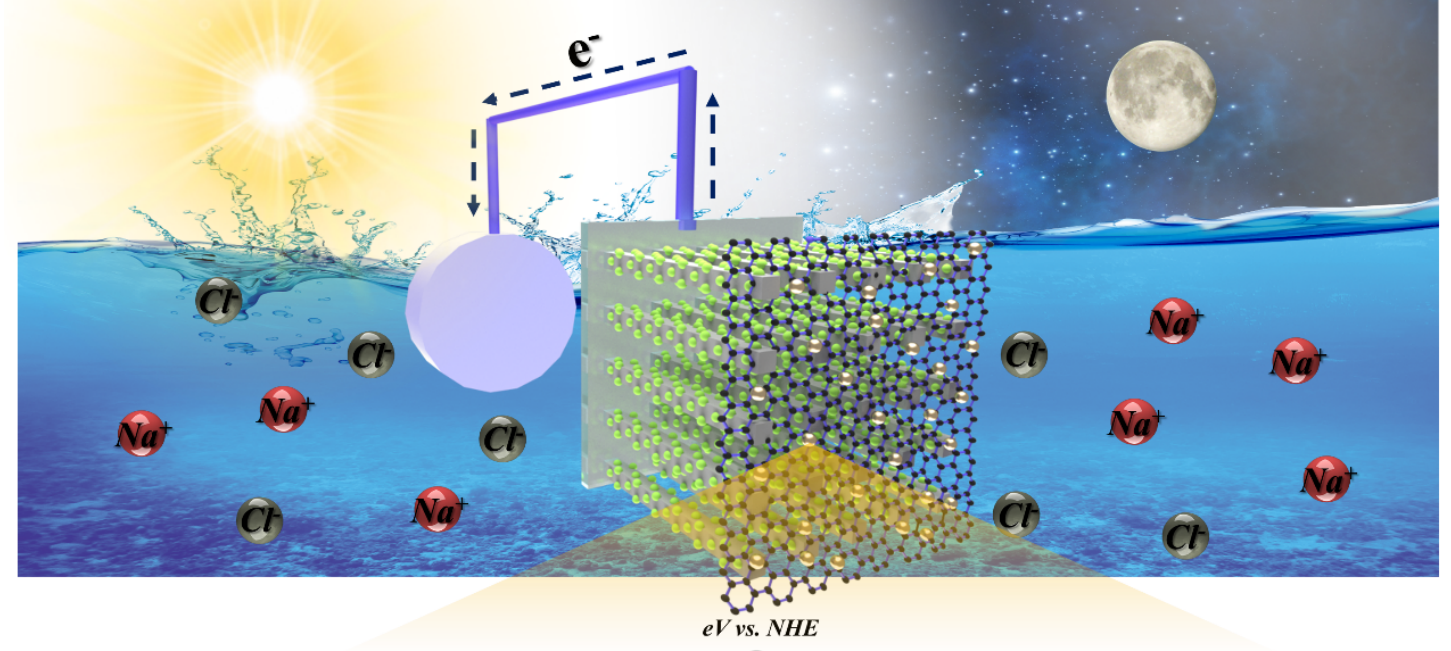

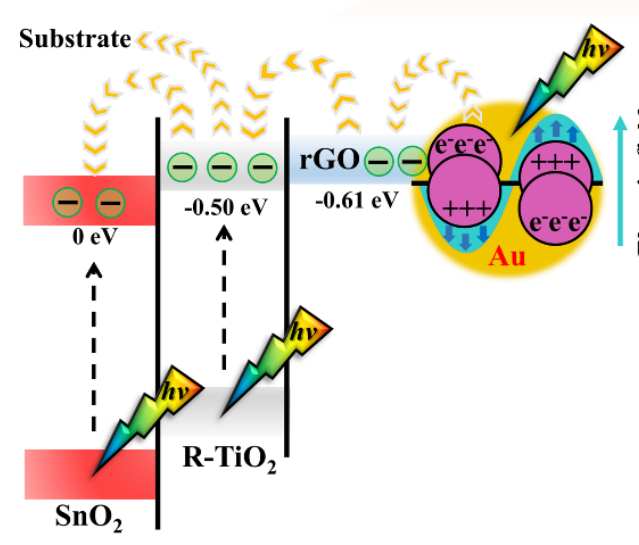

Under visible light illumination

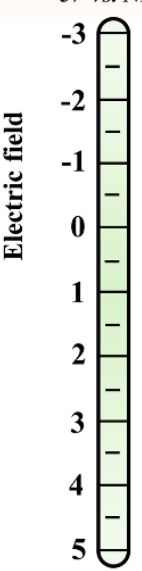

$5 \biguplus$

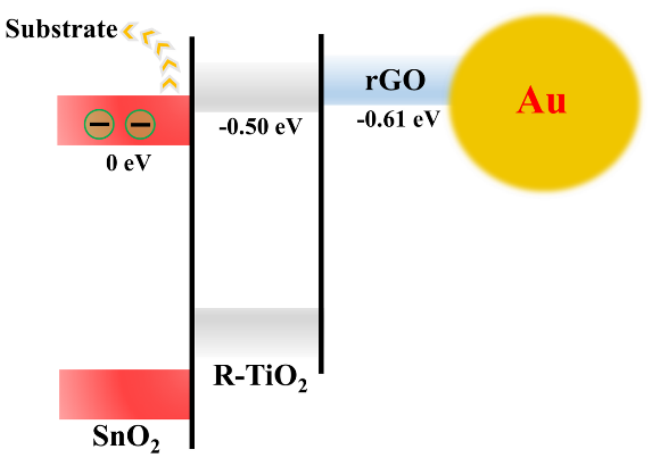

In the darkness

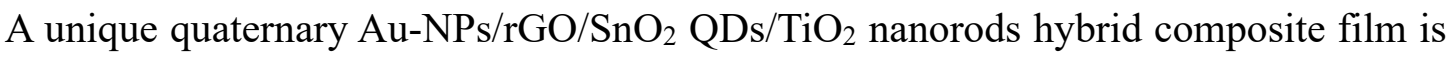
proposed to suppress the 304SS corrosion. The enhanced photocurrent injection from quaternary composite film to the 304SS is determined to be the origin of the excellent photocathodic protection performance. Furthermore, because of the "electrons pool" effect from $\mathrm{SnO}_{2}$, time-delay protection, which can suppress the 304SS corrosion in the dark, is also demonstrated. 